CUADERNOS DE ESTUDIOS GALLEGOS, LXIV Núm. 130 (enero-diciembre 2017), págs. 399-429

ISSN: $0210-847 \mathrm{X}$

DOI: $10.3989 /$ ceg.2017.130.11

\title{
LA VISIÓN DE LA MENDICIDAD EN LA PRENSA DE PONTEVEDRA (1850-1903)
}

\author{
Ana María RodríGuez Martín \\ Doctora en Historia Contemporánea \\ ORCID iD: http://orcid.org/0000-0003-1799-0939
}

Copyright: (C) 2017 CSIC. Este es un artículo de acceso abierto distribuido bajo los términos de una licencia de uso y distribución Creative Commons Attribution (CC-by) España 3.0.

Cómo citar/Citation: Ana María RodríGuez MARTín, "La visión de la mendicidad en la prensa de Pontevedra (1850-1903)”, Cuadernos de Estudios Gallegos, 64, núm. 130 (2017), págs. 399-429, DOI: http://dx.doi.org/10.3989/ceg.2017.130.11 


\section{RESUMEN}

Este texto trata de la consideración social de los pobres, de la estrecha relación entre la mendicidad y la pobreza, y de la evolución de la imagen de los mendigos, incluidos los infantiles, en la sociedad y en la prensa pontevedresa, en la segunda mitad del siglo XIX. En el mismo período, también se valora el resultado de la prohibición de la mendicidad, ordenada por una serie de autoridades municipales, y de algunas de las medidas que se tomaron para hacerla efectiva, y se comparan con las adoptadas en otras ciudades. Asimismo, se analiza el papel jugado por los establecimientos benéficos respecto a la reclusión de los mendigos. Para todo ello se ha utilizado, sobre todo, prensa de Pontevedra y diversas obras de tratadistas de la época. Palabras ClaVe: mendicidad, pobreza, mendigos, prensa, Pontevedra, segunda mitad del siglo XIX.

\section{A VISIÓN DA MENDICIDADE NA PRENSA DE PONTEVEDRA (1850-1903)}

\section{RESUMO}

Este texto trata da consideración social dos pobres, da estreita relación entre a mendicidade e a pobreza, e da evolución da imaxe dos mendigos, incluídos os infantís, na sociedade e a prensa pontevedresa, na segunda metade do século XIX. No mesmo período, tamén valórase o resultado da prohibición da mendicidade, ordenada por unha serie de autoridades municipais, e algunhas das medidas que se tomaron para facela efectiva, e compáranse coas adoptadas noutras cidades. Asi mesmo, analízase o papel xogado polos establecimentos benéficos respecto á reclusión dos mendigos. Para todo iso utilizouse, sobre todo, prensa de Pontevedra e diversas obras de tratadistas da época.

Palabras Clave: mendicidade, pobreza, mendigos, prensa, Pontevedra, segunda metade do século XIX

\section{VIEWS OF MENDICITY IN THE PRESS OF PONTEVEDRA (1850-1903)}

\section{AbStract}

This text deals with the social consideration of the poor, the close relationship between poverty and mendicity and, finally, the gradual change of perception of the beggars, included the children, in the society and in Pontevedra's press, in the second half of the 19th century. We analyse and evaluate as well the results of the ban of mendacity, ordered by some of Pontevedra's local authorities, during the same period. Besides that, we compare these policies with the ones adopted in other cities. Moreover, we study the role played by the charity establishments regarding to the beggars confinement. We have studied, especially, Pontevedra's press and several essayists works of the analysed period.

KEY WORDS: mendicity, poverty, beggars, press, Pontevedra, second half of the $19^{\text {th }}$ century 
Recibido/Received: 07/10/2015

Aceptado/Accepted: 12/01/2017

$\mathrm{E}$ n la segunda mitad del siglo XIX, en España, la mayoría de la población vivía en pésimas condiciones, agravadas por cualquier circunstancia desfavorable añadida, ya fuera una mala cosecha, la carestía de los alimentos, una enfermedad, un accidente, o la falta de trabajo ${ }^{1}$. Para los grupos acomodados, la pobreza tenía una connotación negativa y un carácter permanente, siempre había habido pobres, y se consideraba una característica subjetiva, no el resultado de una determinada estructura social y económica ${ }^{2}$. Muchos de los trabajadores se convertían, eventual o permanentemente, en mendigos, dado que era una salida cuando no había trabajo y faltaba lo básico para subsistir. Había, por tanto, una relación entre pobreza, escasez o falta de trabajo, y mendicidad, sobre todo porque los pobres censados o asistidos eran pocos en relación al número de los que no tenían ayuda alguna. Esta situación se agravó a medida que avanzaba el capitalismo y aumentaba la cantidad de trabajadores que frente a cualquier

\footnotetext{
1 Ildefonso CERDÁ, Teoría General de la Urbanización y aplicación de sus principios y doctrinas a la reforma y ensanche de Barcelona, vol. II, Madrid, Imprenta Española, 1867, págs. 663-673. Francisco Dominguez Adame, "Causas de la excesiva mortalidad en la primera infancia en las grandes ciudades y medios de atenuarlas", en Actas del Congreso Médico Internacional de Sevilla, Sevilla, Imprenta de Carlos M. Santigosa, 1882, págs. 222-223. Juan Sallarés Pla, El trabajo de las mujeres y los niños, Sabadell, Imprenta A. Vives, 1892, págs. 115-117. Práxedes ZANCADA, El obrero en España, Barcelona, Maucci, 1902, págs. 185-197. Jesús María Palomares IbÁÑez, "La condición obrera en La Coruña a finales del siglo XIX", en Jesús de Juana y Xavier Castro (eds.), II Xornadas de Historia de Galicia. Aspectos da realidade galega (Séc. XVI ó XX), Ourense, Diputación Provincial, 1986, págs. 65-66. Esmeralda Ballesteros DonCEL, "El coste de la vida en España (1800-1890). Diferencias entre el salario monetario y el presupuesto familiar" en Manuel González Portilla y Karmele Zarraga Sangroniz (eds.), Actas del IV Congreso de la Asociación de Demografia Histórica, Bilbao, Universidad del País Vasco, 1999, págs. 573-586. Xavier Ibarzabal Aramberri, "Pobreza y mendicidad en Donostia a finales del siglo XX", Boletín de la Real Sociedad Bascongada de los Amigos del País, 1 (1999), págs. 126 y 136. Ana María Rodríguez Martín, Las mujeres y la beneficencia en la segunda mitad del siglo XIX. La Casa Provincial de Maternidad y Expósitos de Barcelona, 1853-1903, tesis doctoral, Universidad de Barcelona, 2005, págs. 83-91.

2 Antoni JUTGLAR, “Actitudes conservadoras ante la realidad obrera en la etapa de la Restauración", Revista del Trabajo, 25 (1969), págs. 45-71. Horacio CAPEL y Mercè TATJER, "Reforma social, serveis asistencials $i$ higienisme a la Barcelona de final del segle XIX (1876-1900)", en Cent anys de salut pública a Barcelona, Barcelona, Ayuntamiento de Barcelona, 1991, pág. 34. Ramón MuÑIz de las Cuevas, O pobo oculto: pobreza y acción social en Galicia, Vigo, A Nosa Terra, 1996, pág. 48.
} 
adversidad no tenían ninguna protección y, además, no podían contar con los establecimientos de beneficencia, dedicados, principalmente, a los niños y a los viejos desvalidos ${ }^{3}$.

Este artículo tiene como objeto el estudio del grupo de pobres, incluidos los niños, que mendigaban de forma ocasional o permanente en Pontevedra. Hemos tenido en cuenta el período comprendido ente los años 1850 y 1903 porque viene marcado por dos leyes muy importantes, la Ley de Beneficencia de 1849 y la Ley sobre vagancia y mendicidad de los menores de 16 años, de 1903. El objetivo de este artículo es el análisis de la consideración social que tenían los mendigos, así como la evolución de las posturas ante el limosneo y la relación de este cambio con la situación económica de la época. Además, vamos a considerar las medidas que se tomaron para reducir el número de mendigos. A partir de este panorama global, iremos al particular, analizando cómo reflejaba la prensa, especialmente la de Pontevedra, la mendicidad, así como las soluciones que proponía y los resultados de las medidas que se tomaron para acabar con ella ${ }^{4}$. Igual proceso seguiremos respecto a la mendicidad infantil, de la que analizaremos las causas y las consecuencias apuntadas por los reformadores sociales de la época.

Para confeccionar este artículo hemos analizado, del período que consideramos, dos revistas especializadas en temas benéficos, La Voz de la Caridad y Revista de beneficencia, sanidad y establecimientos penales, así como obras de diversos tratadistas y prensa variada, sobre todo de Pontevedra, fijándonos especialmente en las noticias y artículos de la sección local porque creemos que era la que mejor reflejaba la postura de la sociedad pontevedresa ante la mendicidad. Hemos seguido el mismo criterio para los periódicos de las otras provincias gallegas.

La prensa de Pontevedra la hemos consultado en el Museo de esta ciudad y en la Biblioteca del Archivo de la Diputación Provincial de Pontevedra, y para examinar los años y números que no se encontraban en estas instituciones hemos

\footnotetext{
3 Julián JUdERÍAs, El problema de la mendicidad en los grandes centros de población, Madrid, Imprenta de J. Sastre y Cia., 1909, pág. 32. Mariano Esteban DE VeGA, "La asistencia liberal española: beneficencia pública y previsión particular”, Historia social, 13 (1992), págs. 123, 124 y 138. Lola VALVERdE LAMSFus, "Estrategias de supervivencia de las mujeres pobres en Guipúzcoa. Los casos de San Sebastián y Tolosa (1885-1915)", Historia Contemporánea, 44 (2012), pág. 188 [en línea], disponible en <http://www.ehu. eus/ojs/index.php/HC/article/view/6610> [consulta: 3-4-2015].

4 Hemos hecho una breve comparación con la prensa de Sevilla. Para ello hemos utilizado el periódico El Porvenir, de 1850 a 1867, y diversas obras: Custodio Velasco Mesa, "La mendicidad en el discurso de la prensa sevillana, 1898-1900: de "problema social" a "amenaza de la multitud miserable", Revista de Historia Contemporánea, 6 (1995), págs. 241-264. Custodio Velasco Mesa, Los nombres de la "cuestión social”. Discursos y agitaciones obreras: Lieja y Sevilla en el tránsito de los siglos XIX y XX, Sevilla, Diputación Provincial, 2003. María del Carmen Giménez MuÑoz, El Asilo de Mendicidad de San Fernando (1846-1900), Sevilla, Universidad de Sevilla, 2006. María del Carmen GimÉnEz MuÑoz, "La mendicidad en la capital hispalense (1850-1900): bandos municipales", Archivo Hispalense, 273-275 (2007), págs. 118-137.
} 
recurrido a la Hemeroteca de Galiciana, Biblioteca Dixital de Galicia, a través de la que también hemos examinado diversos periódicos gallegos.

\section{LA CONSIDERACIÓN SOCIAL DE LOS POBRES EN ESPAÑA}

A lo largo de la segunda mitad del siglo XIX se fue generalizando la división de los pobres en dos grupos. Uno era el de los que estaban domiciliados y soportaban con humildad y resignación su situación y, en caso de limosnear, lo hacían con autorización municipal. El otro grupo era el de los mendigos sin permiso alguno, en ocasiones vagabundos, que estaban apartados ocasional o definitivamente del mundo laboral ${ }^{5}$. Estas dos versiones de la pobreza tenían diferente consideración social. La primera era vista por quienes la padecían, y por la comunidad en la que se manifestaba, como una realidad inamovible e intemporal. La segunda expresión de la pobreza era criticada por la sociedad, que la consideraba un desorden moral, un peligro social y un elemento que, procedente del campo, afeaba la imagen de las ciudades ${ }^{6}$. Para controlar esta última modalidad de pobres se legisló especialmente y se crearon más establecimientos para recluirlos, como los hospicios y los asilos de mendicidad ${ }^{7}$.

En el período que consideramos, fueron cada vez más numerosas las obras sobre la mendicidad. Algunos tratadistas diferenciaban la que obedecía a una extrema necesidad de la que era voluntaria, y se declaraban partidarios de atender solo a los que practicaban el limosneo como último recurso, asilándolos en establecimientos de beneficencia o bien suministrándoles socorros domiciliarios ${ }^{8}$. Otros autores, sin embargo, defendían la prohibición total de mendigar. Esta postura, que fue cobrando fuerza conforme avanzaba la segunda mitad del siglo XIX sostenía que la mendicidad desacreditaba a las ciudades que la permitían ${ }^{10}$ y que

\footnotetext{
5 Concepción Arenal, "La Caridad en Ávila”, La Voz de la Caridad, 177 (15-7-1877), pág. 135. Fermín Hernández Iglesias, "El mal social”, La Voz de la Caridad, 262 (1-2-1881), pág. 303.

6 Pedro Carasa Soto, Pauperismo y revolución burguesa: Burgos, 1750-1900, Valladolid, Universidad de Valladolid, 1987, págs. 257-259. Fernando López Mora, "Mendicidad y acción social en la Córdoba de la Restauración", Boletín de la Real Academia de Córdoba de Ciencias, Bellas Letras y Nobles Artes, 65 (1994), págs. 360 y 363, [en línea], disponible en <http://www.helvia.uco.es/xmlui/bistream/ handle/10396/.../braco127_1994_1.pdf> [consulta: 9-4-2015].

7 Fernando DíEz RodríGUEz, "Estructura social y sistema benéfico asistencial en la ciudad preindustrial", Historia social, 13 (1992), pág. 108.

8 Ramón TAmariz y Eguía, Estudio sobre la vagancia y la mendicidad voluntaria, Madrid, Tipografía de los Huérfanos, 1890, págs. 60-61.

9 Pedro Felipe Monlau, De la supresión de la mendicidad y organización de las Juntas de Caridad, Madrid, Imprenta del Colegio de Sordo-Mudos, 1851, págs. 23-24. Joaquín SALARICH, Higiene del tejedor, Vic, Imprenta Soler Hermanos, 1858, pág. 53.

10 Joaquín Nin y Tudó, Tres problemas: la extinción de la mendicidad, mejorar la situación del proletariado, instrucción popular, Barcelona, Luis Tasso impresor, 1901, págs. 7-8. Pablo Alzola y MinONDO, La mendicidad y la vagancia, Bilbao, Imprenta de la Casa de Misericordia, 1902, pág. 7.
} 
los mendigos eran unos parásitos e, incluso, unos malvados, "Por punto general, los que se dedican a la mendicidad (...) son personas dotadas de malos instintos y enemigas del trabajo"11 "la mendicidad encubre muchas veces un abismo sin fondo de podredumbre y decadencia moral"'12. Concepción Arenal, que en 1861 sostenía la libertad de mendigar para los pobres que no pudieran trabajar ni valerse por sí mismos ${ }^{13}$, años después abogaba por la prohibición total ${ }^{14}$,

Hoy, después de haber vivido y observado, hemos variado de opinión (...) y creemos que la mendicidad rebaja, envilece, desmoraliza, y que el mendigo, si lo es habitualmente, aunque lo sea por necesidad debe borrarse del número de los hombres dignos, y por regla general, de los honrados ${ }^{15}$.

Algunos periódicos de Pontevedra también, a lo largo del período que examinamos, clasificaban a los pobres, y consideraban que sólo los vergonzantes y los que solicitaban pan y trabajo eran merecedores de ser socorridos con limosnas y de ser incluidos en el padrón de pobres ${ }^{16}$. La mendicidad se consideraba una enfermedad moral que abocaba al crimen, "La mendicidad es gangrena (...) hermana de la vagancia, madre del crimen"17, y sólo se justificaba si era accidental. Los pobres auténticos eran los vergonzantes, los que no hacían pública su pobreza,

Qué diferencia entre esos profesionales de la mendicidad y el verdadero pobre, oculto, vergonzante, o al que la extrema necesidad lleva a pedir accidentalmente en la calle (...) La falsa mendicidad debiera ser en efecto, objeto de rigurosas medidas que impidiesen esa asquerosa manifestación de la vagancia y el vicio. En esta ciudad, abundan los pobres de oficio, que explotan los caritativos sentimientos del pueblo robando a los verdaderos pobres su sustento de la sociedad ${ }^{18}$.

\footnotetext{
${ }_{11}$ Luis Vega-Rey, Pobreza y mendicidad, Madrid, Imprenta Enrique Teodoro, 1885, pág. 31.

12 José Leopoldo Feu, Extinción de la mendicidad, Barcelona, Ateneo Catalán, 1862, pág. 10.

13 Concepción Arenal, La beneficencia, la filantropía y la caridad, Madrid, Imprenta del Colegio de Sordomudos y de Ciegos, 1861, pág. 86.

${ }^{14}$ Concepción Arenal, "De la mendicidad”, La Voz de la Caridad, 156 (1-9-1876), pág. 178.

15 Concepción Arenal, "Al pueblo de su naturaleza”, La Voz de la Caridad, 245 (15-5-1880), pág. 63.

16 "El Buscapié”, El Buscapié, 64 (21-7-1867). "Los falsos pobres”, La Opinión, 400 (8-6-1897). "La mendicidad en Pontevedra, II", El Diario de Pontevedra, 5.319 (8-7-1901). Muchos de los periódicos gallegos consultados no hacían constar el número de página.

${ }^{17}$ M. R. Blanco-Belmonte, "Españolería", La Correspondencia gallega, 3.004 (15-1-1900), [en línea], disponible en $<\mathrm{http}$ ://www.galiciana.bibliotecadegalicia.xunta.es $>$ [consulta: 14-11-2016].

18 "Los falsos pobres", El Áncora, 46 (14-6-1897).
} 
Esta postura de la prensa se producía en una ciudad como Pontevedra que, aunque disfrutó de una reactivación económica en la Década Moderada, continuada a lo largo de la segunda mitad del siglo XIX, siguió siendo una pequeña capital de provincia, con un cierto papel burocrático y comercial, pero escasamente industrializada, por lo que presentaba una oferta de trabajo limitada y salarios bajos. En la provincia de Pontevedra, al igual que en el conjunto de Galicia, la mayoría de la población activa vivía del sector primario y soportaba unas precarias condiciones de vida, agravadas por las epidemias y los malos años agrícolas ${ }^{19}$. La prensa recogía estas situaciones, como la que se produjo en 1880, después de una serie de cosechas insuficientes que provocaron que muchos campesinos se trasladaran a las ciudades en busca de auxilios ${ }^{20}$,

\section{La provincia de Pontevedra, que también sufre el flagelo terrible del hambre, pone el grito en el cielo pidiendo la ayuden (...) Familias enteras se ven por doquiera, en cuyos rostros se retrata el hambre y la aflicción de que están poseídos ${ }^{21}$.}

\footnotetext{
19 "Vigo, 23 de febrero", La Oliva, 7 (23-2-1856), [en línea], disponible en <http://www.galiciana.bibliotecadegalicia.xunta.es> [consulta: 9-11-2016]. "Memoria elevada a Su Magestad por la Junta de Caridad de las cuatro provincias de Galicia”, El Iris de Galicia, 24 (22-7-1857), pág. 2, [en línea], disponible en <http:/www.galiciana.bibliotecadegalicia.xunta.es> [consulta: 9-11-2016]. Censo de la población de España según el empadronamiento verificado el 31-12-1887, vol. II, Madrid, Dirección General del Instituto Geográfico y Estadístico, 1892, págs. 484-485 y 572-573. Cosme FERNÁNDEZ Soler, Descripción de Pontevedra, Pontevedra, Imprenta de la Unión Republicana, 1890, pág 75. Julio Hernández Borge, Dinamismo y estructura de la población de Pontevedra, 1900-1970, Santiago de Compostela, Universidad de Santiago, 1974, págs. 124-125. M. ' Xosé Rodríguez GAldo, "A economía en Galicia no século XIX”, en Jesús de Juana y Xavier Castro (dirs.), II Xornadas de Historia de Galicia. Aspectos da realidade galega (Séc. XVI ó XX), Ourense, Diputación Provincial, 1986, págs. 129-134. Carlos F. Velasco Souto, A sociedade galega da Restauración na obra literaria de Pardo Bazán (1875-1900), [s.1., s.n.], d.1. 1987, págs. 190-193. José Antonio LóPez TABOADA, La población de Galicia, 1860-1991, A Coruña, Fundación Caixa Galicia, 1996, pág. 242. Antonio de la Peña Santos, Luis Juega de Guereñu Polán, y Luis López de Guereñu Polán, Historia de Pontevedra, A Coruña, Vía Láctea, 1996, págs. 165-167, 263, 305 y 321-327. Xaquín Fernández Leiceaga, "Poboación e crescimento económico na Galiza do século XX”, en Jesús de Juana y Xavier de Castro (dirs.), XXornadas de Historia de Galicia. Grandes transformacións na Historia contemporánea de Galicia, Ourense, Diputación Provincial, 1998, pág. 127. Carlos Díaz Martínez, Víctor F. Freixanes y Xosé Fortes Bouzán, A memoria de Pontevedra, Vigo, Edicions Xerais, 2001, pág. 123. Luis Alonso Álvarez, "La crisis de la economía tradicional: continuidad y cambio en la Galicia del siglo XIX”, en Jesús de Juana y Julio Prada (coords.), Historia contemporánea de Galicia, Madrid, Ariel, 2005, págs. 41, 45, 53, 54, 72 y 73. Xavier castro, Historia da vida cotiá en Galicia. Séculos XIX e XX, Vigo, Nigratea, 2007, págs. 27-33, 68, 69, 90 y 97-100.

20 "Sobre el amago de la pobreza en Galicia" y "Correspondencia compostelana", El Gallego, 40 (25-1-1880), págs. 5-6 y 1-2, respectivamente, [en línea], disponible en <http://www.galiciana. bibliotecadegalicia.xunta.es> [consulta: 10-11-2016]. Manuel Murguía, "La miseria en Galicia", La Ilustración gallega y asturiana, 14 (20-5-1880), pág. 177. "El hambre en Galicia”, La Ilustración gallega y asturiana, 16 (8-6-1880), pág. 204. "Pobre Galicia” y "Socorramos a Galicia”, El Gallego, 11 (15-8-1880), pág. 5, [en línea], disponible en <http:/www.galiciana.bibliotecadegalicia.xunta.es $>$ [consulta: 10-11-2016]. 21 “¡Una palabra más!”, El Gallego, 11 (15-8-1880), págs. 4 y 5, [en línea], disponible en <http://www. galiciana.bibliotecadegalicia.xunta.es> [consulta: 10-11-2016].
} 
La miseria de los infelices habitantes de la montaña les obliga a buscar algún alivio en las ciudades (...) los constructores de obras se ven asediados por estos desgraciados que tratan honradamente de ganarse el sustento de que carecen, pero no pueden aplicarlos a otra cosa que como peones, y de esta clase hay más de los suficientes avecindados dentro de la población ${ }^{22}$.

En Sevilla, también algunos periódicos diferenciaban la pobreza honrada y virtuosa, de la viciosa y holgazana. Esta última era criticada, mientras que los verdaderos pobres eran calificados de hermanos y se consideraba que merecían ser asistidos. Pero si en la década de los cincuenta del siglo XIX parte de la prensa opinaba que era correcto que se les permitiera limosnear, en la década de los sesenta la mendicidad era considerada perniciosa, un modo de vivir, más cómodo que otro cualquiera ${ }^{23}$. En la Sevilla de la segunda mitad del siglo XIX, caracterizada por los fuertes desequilibrios sociales que se agudizaban en los años de crisis, con una gran parte de la población viviendo en el límite de la subsistencia y sufriendo, además, epidemias e inundaciones ${ }^{24}$, las autoridades trataban de contener la marea de mendigos y marginados, pero sin éxito alguno ${ }^{25}$. Es más, la crisis de los últimos años del siglo XIX y los primeros del XX propiciaron un repunte de la mendicidad, calificado de alarmante por la prensa ${ }^{26}$.

Respecto a la mendicidad infantil, muchos tratadistas eran partidarios de su prohibición total porque consideraban que era inducida y conllevaba la explotación del menor, su corrupción y degradación ${ }^{27}$. Concepción Arenal opinaba, además, que las familias de los niños mendigos, aunque en algunos casos eran dignas de

\footnotetext{
22 "Ecos de Galicia”, El Gallego, 11 (15-8-1880), pág. 89, [en línea], disponible en <http://www.galiciana. bibliotecadegalicia.xunta.es> [consulta: 10-11-2016].

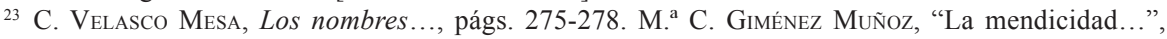
págs. 120.

24 Philippe Hauser, Estudios médicos de Sevilla, Madrid, Librería de Victoriano Suárez, 1884, págs. 258259. Nicolás Salas, Sevilla: crónicas del siglo XX, vol. I, Sevilla, Universidad de Sevilla, 1991, págs. 41-44, 106-108 y 121.

25 Alfonso Braojos Garrido, Historia de Sevilla. Vol. I, Sevilla en el s. XX (1868-1950), Sevilla, Universidad de Sevilla, 1990, págs. 34-36 y 50. Nicolás García García y Gonzalo Butrón Prida, "La realidad social andaluza en el siglo XIX”, en Leandro Álvarez Rey y Encarnación Lemus López (eds.), Historia de Andalucía contemporánea, Huelva, Universidad de Huelva, 1998, pág. 207.

26 J. Manuel Cuenta Toribio, Historia de Sevilla. Del Antiguo al Nuevo Régimen, Sevilla, Universidad de Sevilla, 1986, págs. 137-142, 260-265 y 284. C. Velasco Mesa, Los nombres..., págs. 248-254.

27 Concepción Arenal, "La mendicidad" y "Los niños", La Voz de la Caridad, 155 y 158, respectivamente (15-8-1876 y 1-10-1876, respectivamente), págs. 162-163 y págs. 212-213, respectivamente. "El niño de trapos", La Voz de la Caridad, 231 (15-10-1879), pág. 233. Julio CARdín ZAPata, "Pobres niños”, La Voz de la Caridad, 315, (15-4-1883), pág. 45. Concepción Arenal, "Niños expósitos y niños mendigos", Boletín de la Institución Libre de Enseñanza, XI, (1887), pág. 370. Marta SANTOS SACRISTÁN, "Una aproximación a la Ley de Mendicidad de 1903”, Revista de la Inquisición, 16 (2012), págs. 236-241.
} 
compasión y debía ayudárseles, en muchísimos otros debería caer sobre ellas el peso de una todavía inexistente y necesaria ley de protección al menor ${ }^{28}$. También algún periódico pontevedrés creía que debía prohibirse la mendicidad infantil,

\begin{abstract}
En Londres se ha creado recientemente una nueva sociedad filantrópica, que tiene por objeto reprimir la mendicidad de los niños (...) ¿No podría en España crearse una sociedad análoga, ya que aqui, por desgracia se explotan también por personas desalmadas a algunos desventurados niños que diariamente vemos en las calles implorando la caridad pública? ${ }^{29}$.
\end{abstract}

La prensa y los reformadores sociales sostenían, además, que la mendicidad determinaba el futuro de los niños, puesto que, en el caso de los varones, les predisponía a la delincuencia y el presidio, y en el de las niñas, a la prostitución ${ }^{30}$, además de provocar en todos ellos un fuerte resentimiento social,

\begin{abstract}
En los pechos de los niños mendigos nacerán en estas noches, anuncio del invierno, los primeros sentimientos de odio que en su impotencia se traducirán en lágrimas que helará el frío, pero los niños serán hombres, y éstos cuando odian no lloran, matan ${ }^{31}$.
\end{abstract}

Estos pequeños, hijos de pedigüeños en bastantes casos, eran obligados a mendigar e, incluso, eran alquilados a otros mendigos que conseguían así mayores limosnas, que aumentaban si las criaturas presentaban alguna deformidad o discapacidad psíquica o física ${ }^{32}$,

\footnotetext{
${ }_{28}$ Concepción Arenal, “Al pueblo de su naturaleza", La Voz de la Caridad, 246 (1-6-1880), págs. 77-78. 29 "La mendicidad de los niños", La Correspondencia gallega, 2.410 (13-1-1898), [en línea], disponible en <http://www.galiciana.bibliotecadegalicia.xunta.es> [consulta: 14-11-2016].

30 "La mendicidad en Pontevedra", El Diario de Pontevedra, 5.137 (05-07-1901). Concepción Arenal, "Los niños", El Diario de Pontevedra, 5.295 (22-1-1902). P. GonzÁlez del Alba, "Niños abandonados", El Diario de Pontevedra, 5.367 (22-4-1902). "Una obra justa", Gaceta de Galicia: diario de Santiago, 20 (25-1-1903), [en línea], disponible en <http:/www.galiciana.bibliotecadegalicia.xunta.es $>$ [consulta: 10-11-2016]. Julián JuderíAs, La juventud delincuente, Madrid, Tipografía de Jaime Ratés, 1912, págs. 17-19.

31 Joaquín AzNAR, "Los primeros fríos”, La Correspondencia gallega, 3.536 (30-10-1901), [en línea], disponible en $<\mathrm{http}$ ://www.galiciana.bibliotecadegalicia.xunta.es $>$ [consulta: 14-11-2016].

32 Elena de Cordespall, "Variedades", El Correo de Lugo, 2 (25-5-1860), [en línea], disponible en $<$ http:// www.galiciana.bibliotecadegalicia.xunta.es> [consulta: 10-11-2016]. "Por humanidad", "Los niños mendigos" y "La ciudad", El Regional: diario de Lugo, 4.426, 10.441 y 10.442, respectivamente (10-7-1895, 16-11-1899 y 17-11-1899, respectivamente), págs. 1, 2 y 3, respectivamente, [en línea], disponible en $<$ http://www.galiciana.bibliotecadegalicia.xunta.es $>$ [consulta: 10-11-2016]. "Desde Madrid", El Combate,
} 
Ya se ceden a ciegos para que les sirvan de lazarillos y canten y toquen, ya a otros mendigos válidos mediante retribución o sin ninguna. Otras veces se sacan de las Casas de beneficencia, que, no correspondiendo a su nombre, confian los expósitos a personas que se forman con ellos una renta, obligándolos a mendigar y recoger cada día un minimun de limosna ${ }^{33}$.

Algunas niñas de corta edad importunan al transeúnte pidiendo limosna en las calles, hasta las diez de la noche. Dicen las mendigas que sus padres les pegan si no llevan determinada cantidad, producto de la caridad; lloran con frecuencia y muchas veces gimotean falsamente, simulando llanto ${ }^{34}$.

En otros casos, los menores procedían de hogares de padres trabajadores con larguísimas jornadas de trabajo que les impedían atenderles, o bien la familia se había deshecho porque los progenitores se habían ido cada uno por su lado, o había fallecido uno de ellos o los dos, o bien estaban en presidio. Estos niños compaginaban el vagabundeo y la mendicidad, y vivían tanto de las limosnas como de pequeños hurtos, de recoger colillas y revenderlas, y eran ya desarraigados totales o parciales ${ }^{35}$.

\section{LA IMAgen DE LOS MENDigos EN LA PRENSA PonteVEdRESA}

En Pontevedra, parte de la prensa consideraba que los mendigos daban una imagen muy negativa de la cultura de la ciudad y de sus habitantes, que representaban un obstáculo a la modernidad y un germen de inmoralidad ${ }^{36} \mathrm{y}$, además, que resultaban poco decorativos, "esos infelices que exhiben al transeúnte ciertas enfermedades y ciertas cosas, que ni decoran ni embellecen la población" ${ }^{37}$.

\footnotetext{
46 (4-2-1900). Concepción Arenal, "La educación de la mujer", El Diario de Pontevedra, 5.217 (9-101901). "Niños alquilados", El Áncora, 1.799 (18-9-1903). Josette BordERIEs-GuEREÑA, "Niños y niñas en familia”, en José María Borrás Llop (dir.), Historia de la infancia en la España contemporánea, 1834-1936, Madrid, Ministerio de Trabajo y Asuntos Sociales, 1996, pág. 43.

${ }_{33}$ Concepción Arenal, La instrucción del pueblo, Madrid, Real Academia de Ciencias Morales y Políticas, 1881 , págs. 76 y 77.

34 "Santiago", Gaceta de Galicia, 47 (3-3-1891), [en línea], disponible en <http://www.galiciana. bibliotecadegalicia.xunta.es> [consulta: 10-11-2016].

35 José Estarán Molinero, La Caridad, centenaria: sus primeros años (1898-1910), Zaragoza, Ayuntamiento de Zaragoza, 2000, pág. 69. Félix Santolaria, Marginación y educación, Barcelona, Ariel, 2000, pág. 267. Cándido Ruiz Rodrigo, "Mendicidad infantil, trabajo y educación, en el marco de las políticas sociales de comienzos del siglo XX”, en Doctor Buenaventura Delgado Criado. Pedagogo e historiador, Barcelona, Universidad de Barcelona, 2009, págs. 588-590.

${ }^{36}$ [Sin título], El Diario de Pontevedra, 14 (30-7-1879). "La mendicidad en Pontevedra, II", El Diario de Pontevedra, 5.139 (8-7-1901).

37 “Editorial”, El Diario de Pontevedra, 3 (16-7-1879). "La mendicidad”, El Avisador, 23 (21-2-1881).
} 
Para remediarlo, las ordenanzas municipales de Pontevedra de los años $1850^{38} \mathrm{y}$ $1905^{39}$ prohibieron a las personas que tuvieran malformaciones, mutilaciones o llagas, que las exhibieran y que pidieran limosna, pero el incumplimiento de la normativa fue generalizado ${ }^{40}$,

Continúa por las calles de la población una colonia de mendigos. Lo peor es que entre ellos hay muchos cuyo aspecto es muy desagradable. Digna de consideración es la desgracia pero no por eso debe consentirse que por las calles aparezcan enfermos lazarinos que entran en casas y establecimientos ${ }^{41}$.

En la prensa de Pontevedra se observa una evolución respecto a la mendicidad. Todavía en 1867 encontramos artículos que reconocen la enfermedad, la incapacidad y la pobreza como causas del limosneo,
Es doloroso y por demás desgarrador el cuadro que presenta nues- tra población por las masas de indigentes que recorren sus calles suplicando a los transeúntes una limosna (...) por eso levantamos hoy de nuevo nuestra débil voz en demanda de remedios para estos seres desvalidos, enfermos unos, inútiles completamente otros y miserables todos ${ }^{42}$.

Sin embargo, a partir de 1879, ya vemos artículos quejándose de la multitud de mendigos existentes, a los que se calificaba de vagos que habían convertido el limosneo en medio de vida ${ }^{43}$, "muchos de los que piden se albergan bajo el manto del pobre para ocultar su holganza"4, "confundidos con el verdadero mendigo hay muchos vagos de oficio" 45 " "hay bastante número de los que se toman la mendicidad por un oficio descansado, huyendo del trabajo" 46 . Para sostener estas afirmaciones, se informaba de las obras en las que se necesitaban trabajadores, y no lograban cubrir todas las plazas,

\footnotetext{
38 Ordenanzas municipales de la ciudad de Pontevedra, Pontevedra, Nueva imprenta de las dos A.N. Pazos y Antúnez, 1850, art. 122, pág. 17.

39 Ordenanzas municipales del Excelentísimo Ayuntamiento del Pontevedra, Pontevedra, Tipografía de la Viuda e Hijos de Carrajal, 1905, art. 5, pág. 9.

40 "La mendicidad en Pontevedra", El Diario de Pontevedra, 5.137 (05-07-1901).

41 “Miscelánea”, La Justicia, 1.018 (7-6-1890).

42 "El Buscapié", El Buscapié, 64 (21-7-1867).

43 "Un mal crónico. La mendicidad”, La Correspondencia gallega, 3.983 (7-5-1903).

44 "La mendicidad", El Avisador, 23 (21-2-1881).

45 "La mendicidad en Pontevedra", El Diario de Pontevedra, 5.137 (05-07-1901).

46 "La mendicidad en Pontevedra, II", El Diario de Pontevedra, 5.139 (8-7-1901).
} 
No nos explicamos como haya obreros pidiendo por esas calles, cuando sabemos que en el "Carrucho", donde se construye el puente del ferrocarril sobre el Umia, se admite a todas las personas que se presenten ${ }^{47}$.

Además, a los mendigos se les consideraba unos usurpadores de socorros que deberían ser destinados a los verdaderos pobres ${ }^{48}$,

Nos revelamos, sí, contra esas turbas de vagos que, huyendo y hasta burlándose del trabajo, lo mismo cruzan las aldeas más remotas, que se hacinan en las calles de algunas poblaciones para arrancar hipócritamente de limosnera mano el pedazo de pan por el que suspiran los ancianos enfermos, los jóvenes inútiles para labores materiales, los verdaderos pobres ${ }^{49}$.

Es de desear que por nuestras autoridades se evite este gran mal (la mendicidad) haciendo cuanto sea posible para que desaparezca esa plaga de hombres sanos, aptos para el trabajo, que con la relación de fingidas desgracias o supuestas enfermedades viven en la holganza, roban a los verdaderos pobres y son un peligro constante para la sociedad ${ }^{50}$.

En las dos últimas décadas del siglo XIX y en los primeros años del siguiente, se publican informaciones en la prensa pontevedresa en las que los mendigos aparecen retratados muy negativamente: como aficionados a la bebida ${ }^{51}$ o como simuladores de repatriados de Cuba para obtener mayores limosnas ${ }^{52}$,

El sujeto que pedía limosna por nuestras calles, apoyado en unas muletas no era un repatriado (...) Al fin se descubrió el abuso y el sujeto fue trasladado a la cárcel ${ }^{53}$.

\footnotetext{
47 "De Pontevedra a Carril", La Opinión, 463 (27-8-1897).

48 I. Buceta, "Crónica", El Diario de Pontevedra, 9.144 (17-7-1903).

49 "Editorial", El Diario de Pontevedra, 3 (16-7-1879).

50 "Los falsos pobres", El Áncora, 46 (14-6-1897).

51 “Cocina Económica”, El Diario de Pontevedra, 4.490 (13-7-1899).

52 "Falsos repatriados", La Correspondencia gallega, 3.058 (24-3-1900), [en línea], disponible en <http:// www.galiciana.bibliotecadegalicia.xunta.es> [consulta: 10-11-2016].

53 “Apuntes noticieros”, El Diario de Pontevedra, 4.259 (3-10-1898).
} 
Otras veces, en las noticias se presenta a los pordioseros como sospechosos o autores verdaderos de hurtos y robos ${ }^{54}$, "Los cacos se sospecha sean dos mendigos (...) A él le falta un brazo, y ella tiene en otro una llaga, más o menos auténtica" 55 . También se publican informaciones sobre capturas, efectuadas por la Guardia Civil, de mendigos que se dedicaban al hurto ${ }^{56}$, o se señala a los pordioseros como poseedores de una gran cantidad de dinero que se descubre tras su fallecimiento ${ }^{57}$, o como autores de amenazas e insultos al serle denegada la limosna ${ }^{58}$ e, incluso, como personas susceptibles de convertirse en un peligro social" lado del verdaderamente inhábil para el trabajo, se coloca el holgazán contumaz, materia propia para todo género de desórdenes y perturbaciones" ${ }^{\prime 60}$. Esta nueva visión de los mendigos se produjo al mismo tiempo que los disturbios debidos a la oposición de parte de la población al pago de los impuestos de consumos y de cédulas, y fue paralela al comienzo de la organización de los trabajadores y de la primera huelga obrera en Pontevedra capital ${ }^{61}$. También a lo largo de toda la segunda mitad del siglo XIX fue creciente la sensación, ofrecida por la prensa, de que cada vez los pordioseros eran más numerosos y más invasores ${ }^{62}$,

\section{En Pontevedra adquiere la mendicidad alarmante proporciones; los indigentes asedian en plazas y calles, a las entradas de los templos, en el propio domicilio, y a veces con imposición de mal talante y poco menos que a viva fuerza ${ }^{63}$.}

\footnotetext{
54 "Noticias de Galicia”, "Miscelánea provincial” y "Miscelánea provincial”, La Correspondencia gallega, $2.755,2.843$ y 3.390, respectivamente (13-3-1899, 1-7-1899 y 6-5-1901, respectivamente), [en línea], disponible en $<$ http://www.galiciana.bibliotecadegalicia.xunta.es $>$ [consulta: 10-11-2016]. "Apuntes noticieros" y "Mendigos aprovechados", El Diario de Pontevedra, 5.084 y 9.217, respectivamente (6-5-1901 y 10-10-1903, respectivamente).

55 “Apuntes noticieros”, El Diario de Pontevedra, 4.813 (30-5-1900).

56 “Apuntes noticieros”, El Diario de Pontevedra, 5.352, (3-4-1902).

57 "Miscelánea", La Opinión, 312 (19-2-1897). "Miscelánea provincial”, La Correspondencia gallega, 2.997 (5-1-1900), [en línea], disponible en <http://www.galiciana.bibliotecadegalicia.xunta.es $>$ [consulta: 10-11-2016].

58 "Noticias de Galicia", La Correspondencia gallega”, 2.905 (15-9-1899), [en línea], disponible en < http:// www.galiciana.bibliotecadegalicia.xunta.es> [consulta: 10-11-2016]. "Apuntes noticieros", El Diario de Pontevedra, 5.017 (9-2-1901). “Crónica provincial”, El Áncora, 1.152 (11-6-1901).

59 "La vagancia", El Obrero, 11 (16-5-1898).

60 "La mendicidad en Pontevedra", El Combate, 75 (21-10-1900).

${ }^{61}$ Xavier CAStro, "Introducción á historia do movemento obreiro galego", en Jesús de Juana y Xavier Castro (eds.), III Xornadas de Historia de Galicia. Sociedade e movemento obreiro en Galicia, Ourense, Diputación Provincial, 1986, págs. 186-195. Xosé Fortes Bouzán, Historia de la ciudad de Pontevedra, A Coruña, La Voz de Galicia, 1993, págs. 727-731. Enrique Sotelo Resurrección, Pontevedra, 1840-1915, Pontevedra, Diputación Provincial, 1997, págs. 84, 97 y 99. Aurora Artiaga Rego, "La sociedad gallega (1775-1875)", en Jesús de Juana y Julio Prada (coords.), Historia contemporánea de Galicia, Barcelona, Ariel, 2005, pág. 80 .

62 "Juntas parroquiales", El Buscapié, 13 (29-7-1866). "La mendicidad en Pontevedra" y "Desilusión", El Diario de Pontevedra, 5.137 y 5.272, respectivamente (05-07-1901 y 24-12-1902, respectivamente).

63 "La mendicidad en Pontevedra", El Combate, 75 (21-10-1900).
} 
Este aumento de la mendicidad en Pontevedra que señalaban algunos periódicos se extendía a la practicada por los niños, algunos de ellos muy pequeños, hasta de cuatro años,
¿Por qué no recogerán a dos niñas que, con una desvergüenza y desfachatez impropias a su edad, recorren todos los dias y a todas las horas las calles de la población, pidiendo limosna? ${ }^{64}$.
Por las noches, turbas de niños de ambos sexos (...) pululan por los sitios más céntricos no pudiendo el transeúnte dar un paso sin ser asaltado por innumerables peticiones de socorro ${ }^{65}$.

Son pocos los artículos que achacan la mendicidad infantil a la falta de trabajo, la enfermedad o la muerte de los progenitores ${ }^{66}$. Por regla general, la prensa se fijaba menos en el desamparo de los menores que en su explotación por parte de sus padres u otros mendigos,

\begin{abstract}
Bien puede decírsenos que los padres de esas infelices criaturas tienen que servirse de ellos como tristes mensajeros de la necesidad, por estar aquellos imposibilitados. Puede haber algo de verdad de ello; pero tampoco desconocemos que hay mucho de explotación estudiada en ese medio de mendicidad ${ }^{67}$.

Niños de cuatro y cinco años pululan continuamente por esas calles, en el más completo estado de miseria y abandono, mostrando sus desnudeces por entre los harapos (...) ¿No tienen padres, tutores o guardadores? Quizás sí, la mayor parte; porque la mendicidad en la infancia se aprovecha como una explotación del sentimiento caritativo, por parte de padres que no tienen ningún sentimiento moral, exponiendo a mil peligros la inocencia de esas desgraciadas criaturas $^{68}$.
\end{abstract}

En la prensa pontevedresa aparecían artículos en los que se consideraba a los niños mendigos como una plaga molesta por sus peticiones de limosna, sus gritos

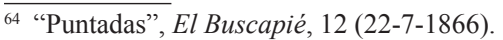

65 "La mendicidad en Pontevedra", El Combate, 75 (21-10-1900).

66 “Caridad infantil”, La Correspondencia gallega, 2.984 (19-12-1899), [en línea], disponible en <http:// www.galiciana.bibliotecadegalicia.xunta.es> [consulta: 10-11-2016].

67 "La mendicidad en Pontevedra, II", El Diario de Pontevedra, 5.139 (8-7-1901).

68 "La mendicidad de los niños", El Diario de Pontevedra, 9.164 (7-8-1903).
} 
y sus correrías, y se insistía sobre el escándalo que causaba verlos vagar todo el día y sobre el futuro que les esperaba, el peligro que suponían para el orden social ${ }^{69}$, la mala imagen que daban de la Ciudad y la conveniencia de tenerlos recluidos ${ }^{70}$,

Desconsolador es el porvenir que espera a estos desgraciados niños (...) de pedir una limosna se pasan a exigirla, de aquí al tomarla; y más tarde truecan la calle por la cárcel, la cárcel por la capilla, y la capilla por el cadalso ${ }^{71}$.

Da una idea mala de nuestra cultura y de esos mismos sentimientos cristianos que niños de cuatro y seis años pululen por la vía pública, sucios y desharrapados (...) pidiendo limosna ¿Hay un Hospicio donde puedan ser atendidos y educados? Pues entonces es un crimen permitirles el que anden rodando por las calles, como desperdicios sociales arrojados al arroyo ${ }^{72}$.

Si nos fijamos ahora en la prensa de Sevilla, en la segunda mitad del siglo XIX, podemos ver que en algunos periódicos también se afirmaba que los mendigos no respetaban las normas de convivencia, afeaban la ciudad, eran molestos, sucios y, además, repulsivos debido a sus llagas y muñones ${ }^{73}$. Al principio del período que consideramos, todavía encontramos informaciones en las que se señalaba la falta de trabajo como la causa de la caída de muchas personas en la mendicidad pero, posteriormente, se apuntaba incluso, en los períodos de crisis y en los meses de paro estacional de los jornaleros, al abandono del trabajo y a la preferencia por limosnear $^{74}$. Ya a finales del siglo XIX, parte de la prensa sevillana consideraba que la mendicidad era el primer paso hacia la delincuencia, y señalaba, al igual que en los años precedentes, que los pedigüeños eran cada vez más numerosos, una plaga ${ }^{75}$, incluidos los niños que mendigaban, que procedían de los barrios más pobres e insalubres, donde la desnutrición crónica infantil era común ${ }^{76}$.

\footnotetext{
69 "Miscelánea", El Anunciador, 3.630 (4-8-1889). Concepción Arenal, "Los niños pobres", El Diario de Pontevedra, 5.610 (27-12-1902).

70 "La mendicidad en Pontevedra", El Combate, 75 (21-10-1900). "La mendicidad de los niños", El Diario de Pontevedra, 9.164 (7-8-1903).

71 "La mendicidad", El Avisador, 23 (21-2-1881).

72 "La mendicidad en Pontevedra", El Diario de Pontevedra, 5.137, (05-07-1901).

73 C. Velasco Mesa, “La mendicidad...”, págs. 248-249 y 251. C. Velasco Mesa, Los nombres..., págs.

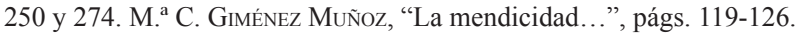

74 C. Velasco Mesa, Los nombres..., pág. 275. M. a C. Giménez Muñoz, El Asilo..., págs. 84-85.

75 C. Velasco Mesa, "La mendicidad...”, págs. 255 y 274. C. Velasco Mesa, Los nombres..., págs. 250

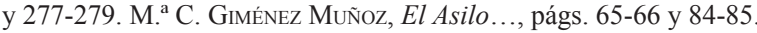

${ }^{76} \mathrm{Ph}$. Hauser, Estudios médicos..., págs. 265-290 y 518-521.
} 


\section{AlgunAS MEDIDAS ADOPTADAS PARA CONTENER LA MENDICIDAD}

Para intentar disminuir el número de pobres y mendigos, como reclamaba parte de la prensa, se tomaron en España, en la segunda mitad del siglo XIX, diversas medidas, pero no buscaban cambiar las estructuras sociales y atacar de raíz el problema de la pobreza, y el de la mendicidad a ella unida, sino convertir a los pordioseros en personas útiles y asegurar el orden público. Una de las medidas adoptadas fue la asistencia puntual, que se producía en las grandes calamidades, como riadas o epidemias, o en los momentos álgidos de las crisis económicas, para amortiguar la tensión social, evitar que los pobres se lanzaran a la calle y frenar el número de niños abandonados y de mendigos que en esas circunstancias aumentaba ${ }^{77}$. La burguesía, y su aliada en las tareas benéficas, la nobleza, aprovechaban estas ocasiones para legitimar su papel social dominante ${ }^{78}$. En Sevilla, en la riada de enero de 1856, se distribuyeron miles de hogazas de pan y raciones de arroz y bacalao, y se recaudó una importante cantidad de reales para los damnificados. Entre los donantes estaban asociaciones conocidas y alabadas por la prensa, como la Real Maestranza de Caballería o la Hermandad de la Caridad, compuestas por lo más granado de la nobleza ${ }^{79}$. En otros casos, eran los ayuntamientos o las comisiones parroquiales los que dispensaban estos socorros puntuales, que solían consistir en la distribución de alimentos ${ }^{80}$.

Respecto a las medidas legislativas relativas a la mendicidad, si bien en el Código Penal de 1848 estaba penada con arresto mayor y sujeción a la vigilancia de la autoridad si no se practicaba con licencia ${ }^{81}$, en el de 1870 no se contemplaba este delito, tan solo se consideraba la vagancia ${ }^{82}$ como una circunstancia agravante $^{83}$.

\footnotetext{
77 Fernando López Mora, Pobreza y sociedad en Córdoba, (1750-1900): de la caridad a la beneficencia pública, Córdoba, Universidad de Córdoba, 1992, págs. 823-824. José María Moro, Las epidemias de cólera en la Asturias del siglo XIX, Oviedo, Universidad de Oviedo, 2003, págs. 207-210.

${ }^{78}$ Elías Mateo Avilés, Paternalismo burgués y beneficencia religiosa en la segunda mitad del siglo XIX, Málaga, Diputación Provincial, 1985, pág. 123.

79 "Distribución de limosnas" y "Ranchos", El Porvenir, 2.519 (10-1-1856). "Pan” y "Acción generosa", El Porvenir, 2.527 (17-1-1856). “Acción laudable” y “Actos oficiales y Beneficencia”, El Porvenir, 2.531 y 2.537 , respectivamente (19-1-1856 y 25-1-1856, respectivamente).

80 “Ecos de Galicia”, El Gallego, 11 (5-8-1880), pág. 7, [en línea], disponible en <http://www.galiciana. bibliotecadegalicia.xunta.es> [consulta: 13-11-2016]. Xosé Ramón BARREIRo FernÁndez, "De Isabel II a la Restauración”, en A Gran Historia de Galicia, vol. XI, A Coruña, Editorial Arrecife, 2007, pág. 122.

${ }^{81}$ Código Penal de 1848, art. 263. Código Penal de España, Barcelona, imprenta de Manuel Saurí, 1850, pág. 71.

82 "Son vagos los que no poseen bienes o rentas, ni ejercen habitualmente profesión, arte u oficio, ni tienen empleo, destino, industria, ocupación lícita, o algún otro medio legítimo y conocido de subsistencia, aún cuando sean casados y con domicilio fijo". Código Penal de 1848, art. 258. Código Penal de España..., pág. 70. En el Código Penal de 1870, la definición de vago es similar.

83 Código Penal de 1870, art. 10. Código Penal de 1870, Valencia, Librería de P. Aguilar, 1889, pág. 20. Fermín Hernández Iglesias, “Gaceta de Galicia, 47 (3-3-1891), El mal social”, La Voz de la Caridad, 280 (1-11-1881), pág. 250.
} 
Sin embargo, la prensa española, al señalar la gran cantidad de mendigos existentes, pedía medidas para limitar o acabar con la mendicidad, especialmente la infantil. También aportaba soluciones, como la del distintivo o chapa que sería dado por los ayuntamientos a los verdaderos necesitados locales, y alababa a las autoridades que adoptaban medidas, que solían ser el envío de los mendigos foráneos a sus pueblos de naturaleza y la reclusión de los pordioseros propios ${ }^{84}$.

Muchos ayuntamientos, a lo largo de la segunda mitad del siglo XIX, publicaron edictos, bandos y ordenanzas prohibiendo totalmente la mendicidad, sobre todo cuando ésta aumentaba en épocas de crisis, aunque otros consistorios la permitían en casos de vejez, discapacidad, viudez o minoría de edad combinada con orfandad $^{85}$. Este diversidad de medidas era denunciada por Concepción Arenal, "En una ciudad se los persigue, en otra se los autoriza, y en la misma pueden ó no pedir, según la persona que mande: en los campos se puede mendigar siempre" ${ }^{\text {"96. Toda }}$ la normativa que pretendía eliminar la mendicidad se reiteraba periódicamente dado su fracaso, pues no atacaba las raíces de la pobreza ${ }^{87}$.

En Pontevedra, a lo largo de la segunda mitad del siglo XIX, algunos periódicos pidieron la prohibición de la mendicidad y la retirada de los mendigos de las calles ${ }^{88} \mathrm{y}$, en algunos casos, que fueran albergados en centros benéficos ${ }^{89}$,

\footnotetext{
84 “Correspondencia", El Eco de Galicia, 87 (24-1-1852), [en línea], disponible en <http://www.galiciana. bibliotecadegalicia.xunta.es> [consulta: 13-11-2016]. "Correspondencia”, La Oliva, 34 (28-5-1856), [en línea], disponible en $<\mathrm{http}$ //www.galiciana.bibliotecadegalicia.xunta.es $>$ [consulta: 14-11-2016]. "Gacetilla", El Iris de Galicia, 11 (7-6-1857), pág. 3, [en línea], disponible en <http://www.galiciana.bibliotecadegalicia. xunta.es> [consulta: 13-11-2016]. Melchor SALVÁ, "Relación histórica de la Sociedad", Revista Económica: periódico agrícola, artístico y comercial de la Sociedad de Amigos del País de Santiago, 57 (15-3-1863), pág. 186. "Noticias regionales", La Ilustración gallega y asturiana, 12 (30-4-1879), pág. 143. "Santiago", Gaceta de Galicia, 172 (31-7-1895), [en línea], disponible en <http://www.galiciana.bibliotecadegalicia. xunta.es> [consulta: 13-11-2016]. Herminia Pernas Oroza, Historia das mulleres en Galicia, época contemporánea, Baiona, Nigratea y Xunta de Galicia, 2011, pág. 147. Encarna Galván GonzÁLez, "Pobreza y mendicidad en Las Palmas de Gran Canaria durante la segunda mitad del siglo XIX. Actitud municipal frente al problema", Boletín Millares Carlo, 15 (1996), pág. 72. Ma Carmen FuenTEs Nieto, "Una institución benéfica en la Málaga del siglo XIX: la Casa de Mendicidad”, Jábega, 93 (2003), pág. 22.

85 J. Estarán Molinero, la Caridad..., pág. 69. José Antonio Torres Ruiz, "Un ejemplo de beneficencia municipal en el s. XIX: el Asilo de Mendicidad de León”, Tierras de León, 126-127 (2008), págs. 114-115 [en línea], disponible en <http:/www.saber.es/web/biblioteca/libros/tierras-de-leon/html/126-127/tierrasde-leon-126-127.pdf $>$ [consulta: 15-9-2015].

${ }^{86}$ Concepción Arenal, "Persecución de mendigos", La Voz de la Caridad, 271 (5-6-1881), pág. 99.

87 Concepción Arenal, "Al pueblo de su naturaleza", La Voz de la Caridad, 244 (1-5-1880), págs. 44-45. Concepción Arenal, Artículos sobre beneficencia y prisiones, Madrid, Librería de Victoriano Suárez, 1901, págs. 428-430. Manuel Cossío y Gómez Aсевo, El problema de la mendicidad en los grandes centros de población, Madrid, Imprenta de J. Sastre y Cia., 1909, págs. 49 y 81. Luz Román PorTAs, La asistencia social en Galicia: el Hospicio de Pobres de Santiago de Compostela (1860-1900), A Coruña, Diputación Provincial, 1989, pág. 72. Elena MAZA Zorrilla, Pobreza y beneficencia en la España contemporánea (1808-1936), Madrid, Ariel, 1999, pág. 19.

88 “Sección Editorial”, El Diario de Pontevedra, 976 (13-5-1885). "Un mal crónico. La mendicidad”, La Correspondencia gallega, 3.983 (6-5-1903), [en línea], disponible en <http://www.galiciana.bibliotecadegalicia.xunta.es> [consulta: 13-11-2016].
} 
Ordenar la retirada de los mendigos de la vía pública... sin cuidarse a donde van, ni si han comido y tienen hogar donde guarecerse sería solemnemente estúpido y egoísta. No pedimos eso. Pedimos que se recoja a los mendigos, se les atienda en un asilo, y se provea a las necesidades de su mísera existencia, en sitio más propio para ello que la calle (...) que una capital, que tiene un Hospital, un Hospicio y una Sociedad de San Vicente de Paúl, no consienta el triste espectáculo que todos los días vemos por las calles ${ }^{90}$.

Otra parte de la prensa insistía en la expulsión de los mendigos que no fueran naturales de la Ciudad, y respecto a los que sí lo fueran, sugería que se les autorizase a limosnear, siempre que padecieran verdadera necesidad y que hubieran pasado un reconocimiento médico. Este último trámite tenía como objetivo eliminar a los aptos para el trabajo y curar a los que mantuvieran enfermedades que movieran a la compasión ${ }^{11}$,

Por diferentes medios explotan algunos individuos los sentimientos generosos del vecindario (...) cosa que creemos puede evitarse con solo impedir que vengan a pordiosear a nuestro pueblo los mendigos de otras partes y autorizar solamente para que lo hagan a los de la ciudad cuyo desvalimiento sea notorio ${ }^{92}$.

Las ordenanzas municipales de Pontevedra de 1850 sólo permitían pedir, y nada más hasta que se creara el Hospicio, cosa que ocurrió en 1853, a los naturales de la Ciudad debidamente autorizados. A los que no contaran con este permiso, o bien estuvieran en condiciones de trabajar, se les consideraría vagos y se les llevaría ante la justicia, pudiendo ser condenados a un arresto de cinco a quince días ${ }^{93}$. Estas ordenanzas no dieron resultado, y hasta el último año que abarca este artículo, e incluso posteriormente, la prensa siguió clamando contra los pordioseros y pidiendo la aplicación de las ordenanzas vigentes,

\footnotetext{
89 "Los estropeados", La Correspondencia gallega, 2.850 (10-7-1899), [en línea], disponible en <http:// www.galiciana.bibliotecadegalicia.xunta.es> [consulta: 13-11-2016].

90 "La mendicidad en Pontevedra", El Diario de Pontevedra, 5.137 (5-7-1901).

91 "La mendicidad en Pontevedra, II" y "Desde cultovedra", El Diario de Pontevedra, 5.139 y 9.152, respectivamente (8-7-1901 y 23-7-1903, respectivamente).

92 "Un mal crónico. La mendicidad”, La Correspondencia gallega, 3.983 (6-5-1903), [en línea], disponible en <http://www.galiciana.bibliotecadegalicia.xunta.es> [consulta: 13-11-2016].

93 Ordenanzas municipales de la ciudad..., art. 121-123 y 127, págs. 20-23.
} 
La mayor parte de los días, y en los que se celebra alguna fiesta o romería en las cercanías de nuestra ciudad, es indecoroso el repugnante espectáculo que presentan las carreteras, a cuyos lados y formando un lucidísimo cordón se ostentan las más asquerosas destrucciones causadas por la enfermedad y la miseria ${ }^{94}$. ¿Se dictan algunas disposiciones acerca de la mendicidad? No lo sabemos y no lo creemos tampoco. Todos los días y muy especialmente en los lunes de cada semana, la población es tomada por asalto por centenares de mendigos que molestan al transeúnte y que ofrecen espectáculos poco agradables ¿Se observan las Ordenanzas municipales? En general, $n o^{95}$.

También en Sevilla, a lo largo de la segunda mitad del siglo XIX, las sucesivas ordenanzas municipales pasaron de permitir la mendicidad en algunos casos a los naturales de la ciudad, después de que el Ayuntamiento hubiera valorado su desvalimiento o minusvalía, a prohibirla sin excepción alguna ${ }^{96}$. En un primer momento, estas disposiciones parecían efectivas, pero todas acabaron en un fracaso, muy criticado por la prensa ${ }^{97}$.

Respecto a la mendicidad infantil, la ley de 26-7-1878 sobre trabajos peligrosos de los niños castigaba a los que cedieran menores a individuos que se dedicaran habitualmente a la mendicidad. En 23-7-1903 se publicó la Ley sobre vagancia y mendicidad de los menores de 16 años, que establecía la prohibición de que éstos pidieran limosna y contemplaba, en caso de reincidencia, la detención y multa de sus padres o tutores, e incluso, la supresión de la guarda y educación, y el ingreso del menor en un establecimiento benéfico. Además, si se trataba de huérfanos, de niños abandonados o de aquellos que no podían ser cuidados por sus padres por falta de medios, el municipio o provincia de origen debería hacerse cargo de su atención y educación ${ }^{98}$. Sin embargo, esta ley no fue observada ${ }^{99}$. En 1908, el periodista Álvaro López Núñez denunciaba la explotación de criaturas por parte de sus padres o de otros mendigos a los que eran alquiladas,

\footnotetext{
94 "Las Ordenanzas Municipales”, La voz de Helenes, 20 (16-12-1883).

95 "Cuestiones locales", La Voz de Helenes, 45 (8-6-1884).

${ }^{96}$ M. ${ }^{a}$ C. Giménez MuÑoz, "La mendicidad...”, págs. 118-135.

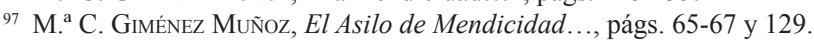

98 Leyes y disposiciones vigentes de Protección a la Infancia, Madrid, Imprenta del Asilo de Huérfanos del Sagrado Corazón de Jesús, 1908, págs. 15-21 y 50-55.

99 Gerardo González Revilla, La protección de la infancia abandonada: abandono y criminalidad de los niños, Bilbao, Tipográfica Popular, 1907, págs. 119-120 y 433. M. SANTOS SACRISTÁn, "Una aproximación...", págs. 258 y 260.
} 
A poco que se ande por las calles de la Corte se encontrará la mujer sucia y harapienta que exhibe dos o tres niños exangües, inanimados y atrépsicos (...) y no faltan desalmados que hacen granjería de las anormalidades orgánicas de la infancia, paseando por lugares públicos niños hidrocéfalos, ciegos, mudos, cretinos o lacerados con terribles estigmas de la piel ${ }^{100}$.

Años más tarde, todavía se seguía viendo a numerosos niños que pedían, y a los que sus explotadores les exigían una determinada cantidad diaria. A estos menores se les vaticinaba la caída en el delito, y si se trataba de niñas, en la prostitución ${ }^{101}$.

En Pontevedra, en los periódicos, se criticaba la falta de resultados a corto plazo de la ley de 1903 citada $^{102}$, pero sabemos que tampoco se vieron a largo plazo porque todavía en 1910 la prensa pontevedresa seguía quejándose de la gran cantidad de mendigos infantiles,

Lo mismo en la Herrería que en los andenes de la Estación ferroviaria, a la puerta de los templos o en la Alameda, cotidianamente os encontraréis (...) con pequeñuelos descalzos cubiertos de vestiditos mugrientos y remendados que os piden con voz lastimera "una chica"”103.

\section{Los CENTROS BENÉFICOS DE ACOGIDA DE POBRES Y MENDIGOS}

Los centros públicos que acogían a pobres y mendigos solían tener carácter municipal, lo que permitía a los ayuntamientos atender sólo a los pobres propios, excluyendo a los de procedencia rural, que eran numerosos ${ }^{104}$. La existencia de estas instituciones benéficas proporcionaba una buena excusa para la represión de la mendicidad y la vagancia: al socorrer a los auténticos pobres, el que pedía lo hacía por vicio. Sin embargo, aunque a partir de 1852 aumentó el número

\footnotetext{
${ }^{100}$ Álvaro LóPEZ NúÑEz, Los inicios de la protección social a la infancia en España, Madrid, CEPE, 1992, pág. 125 .

${ }^{101}$ Julián JuderíAs, La infancia abandonada, Madrid, Tipografía de Jaime Ratés, 1912, págs. 8-10. Pedro TRINIDAD FERnÁndEZ, "La infancia delincuente y abandonada", en José María Borrás Llop (dir.), Historia de la infancia en la España contemporánea, 1834-1936, Madrid, Ministerio de Trabajo y Asuntos Sociales, 1996, pág. 480.

${ }^{102}$ Concepción Arenal, “Los niños”, La Correspondencia gallega, 4.176 (29-12-1903), [en línea], disponible en $<$ http://www.galiciana.bibliotecadegalicia.xunta.es $>$ [consulta: 13-11-2016].

${ }^{103}$ Augusto BArreiro, "Una chica, señoritino”, El Progreso, 184 (12-6-1910).

${ }^{104}$ Reglamento del Asilo Local de Mendicidad, A Coruña, Tipografía "La Gutemberg”, 1895, art. 2, pág. 3. Antonio Guerola, "Los Asilos del Pardo", La Voz de la Caridad, 95 (15-2-1874), pág. 358. "La organización de la caridad”, La Voz de la Caridad, 137 (15-11-1875), pág. 263.
} 
de asilos y hospicios, debido a que el Reglamento que desarrollaba la Ley de Beneficencia de 1849 establecía su existencia en todas las capitales de provin$\operatorname{cia}^{105}$, la realidad es que resultaron insuficientes para atender a la enorme masa de necesitados, sobre todo en épocas de crisis y epidemias ${ }^{106}$. Estos centros tenían un carácter represivo y aislante muy notable, dado que en muchas ocasiones allí eran conducidos los mendigos por la fuerza y allí debían permanecer un tiempo variable, en el que apenas podían recibir visitas de los familiares y las salidas al exterior eran escasas ${ }^{107}$ y solían estar vigiladas,

\begin{abstract}
Siempre que el tiempo lo permita, saldrán los acogidos a paseo al campo, los dias de fiesta, vestidos aseadamente y formados, acompañados por el Rector y la Rectora. Conviene que alguna vez pasen por las calles de la ciudad para que el pueblo los vea y pueda juzgar del resultado de su limosna ${ }^{108}$.
\end{abstract}

Los centros de asilo de pobres y mendigos tenían también carácter reeducador, mediante la imposición de una rígida jerarquía, una estricta disciplina, una programación exhaustiva de cada jornada y un reglamento interno, que si no era respetado conllevaba castigos muy severos, que se fueron suavizando conforme avanzaba el período que consideramos ${ }^{109}$. Esta faceta reeducadora se completaba con el trabajo, que era obligatorio porque, aparte de ser una fuente de ingresos,

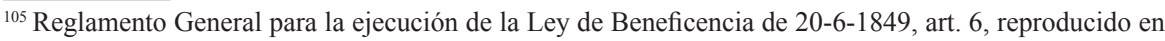
Elena MaZa Zorrilla, Pobreza y asistencia social en España, siglos XVI al XX, Valladolid, Universidad de Valladolid, 1987, pág. 232.

${ }^{106}$ Miguel Blanco Herrero, De la Beneficencia pública en España, Madrid, J.M. Pérez, 1869, págs. 8-10. "La Casa de Caridad de Barcelona", Revista de beneficencia, sanidad y establecimientos penales, 65 (noviembre de 1878), pág. 1.042. Ángel Bahamonde Magro y Julián Toro Mérida, "Mendicidad y paro en el Madrid de la Restauración”, Estudios de Historia Social, 7 (1978), pág. 375. Francisco Miguel EsPINO JiMÉNEZ, "Actitud social y regulación de la mendicidad en el liberalismo: las normas contra "vagos" en la Córdoba isabelina”, Ámbitos, 17 (2007), pág. 38, [en línea], disponible en <http://dialnet.unirioja.es/ servlet/extaut?código=519912> [consulta: 8-4-2015].

${ }^{107}$ Reglamento del Asilo de Mendicidad de San Bernardino, Madrid, Junta Municipal de Beneficencia, 1855 , art. 7, pág. 5. Reglamentos para el régimen interior de los establecimientos provinciales de beneficencia, Salamanca, Imprenta del Hospicio, 1886, pág. 50.

${ }^{108}$ Reglamento interior para el Asilo de Mendicidad de La Coruña, A Coruña, Imprenta del Hospicio Provincial, (s.a.) (La fecha fin del texto: 1862), pág. 6.

${ }^{109}$ Ramón Codina Langlín, Organización de la Casa Provincial de Caridad y de la Casa Provincial de Maternidad y Expósitos de Barcelona, Barcelona, Imprenta de la Casa Provincial de Caridad, 1889, págs. 8-9. Pedro CARAsa Soto, "La Historia y los pobres: de las bienaventuranzas a la marginación", Historia Social, 13 (1992), págs. 84-85. Cándido Ruiz Rodrigo e Irene PALACio Lis, Pauperismo y educación. Siglos XVIII y XIX, Valencia, Universidad de Valencia, 1995, pág. 127. Josep PuY I JuAnico, Pobres, desvalguts $i$ asilats: caritat $i$ beneficència a la Catalunya del segle XIX, Barcelona, Publicacions de l'Abadia de Montserrat, 2009, págs. 149-151.
} 
aunque escasa, para el establecimiento benéfico, favorecía que los asilados se dedicaran a una actividad productiva sujeta a horarios. Los responsables de estos establecimientos afirmaban, además, que el trabajo alejaba a los acogidos, sobre todo a los niños y jóvenes, de los vicios y de la delincuencia que conllevaban la ociosidad, y los convertía en personas laboriosas que contribuirían a la prosperidad del país ${ }^{110}$.

La reclusión de los mendigos era bien vista por parte de la prensa pontevedresa, que sugería, sobre todo en época de epidemias, la limpieza de las calles, la supervisión de los mercados y, especialmente, la asistencia y recogida de los menesterosos en el Hospicio, además de un severo control higiénico de los establecimientos benéficos ${ }^{111}$. Los periódicos recogían el sentir de algunas personas que consideraban que los mendigos eran un peligro sanitario. Según los médicos de la época, las enfermedades, sobre todo las epidémicas, se cebaban en la población más necesitada debido a las malas condiciones en las que vivía y, según algunos tratadistas, también a causa de sus vicios, por lo que los pobres, y sobre todo los mendigos, representaban un peligro para la salud general ${ }^{112}$.

En Pontevedra, en 1853, cuando el cólera y la crisis económica provocaron el aumento del número de pobres y pedigüeños, la Asociación Benéfica de Señoras, formada por una serie de mujeres pertenecientes a las familias más importantes de la Capital, creó el Hospicio con el objetivo de acoger a los pobres a los que la necesidad obligaba a mendigar. Pero la realidad es que su capacidad, a lo largo del período que analizamos, fue muy reducida ${ }^{113}$ y resultaba insignificante respecto al número de habitantes de Pontevedra y de mendigos censados ${ }^{114}$.

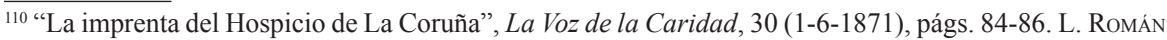
Portas, La asistencia social..., págs. 26 y 54. Irene Palacio Lis y Cándido Ruiz Rodrigo, Redimir la inocencia: historia, marginación infantil y educación protectora, Valencia, Universidad de Valencia, 202, págs. 184-185.

${ }^{111}$ Sin título, El Ferro-carril, 35 (4-6-1854), pág. 3. "Los amigos de los pobres” y “Es conveniente continuar el método preservativo del cólera morbo?”, El Progreso, 22 y 26, respectivamente (22-10-1865 y 9-11-1865). "Las ordenanzas municipales", La Voz de Helenes, 20 (16-12-1883).

112 J. Varela de Montes, sin título, Boletín del cólera, 11 (30-5-1854), pág. 2, [en línea], disponible en $<$ http://www.galiciana.bibliotecadegalicia.xunta.es $>$ [consulta: 14-11-2016]. Ignacio LlorENS y GALLARD, La mendicidad en Barcelona, Tipografía de la Casa Provincial de Caridad, Barcelona, 1892, pág. 13. José Luis Fresquet Febrer, Francisco Méndez Álvaro (1806-1883) y las ideas sanitarias del liberalismo moderado, Ministerio de Sanidad y Consumo, Madrid, 1990, págs. 131-165.

${ }^{113}$ El número de asilados existentes, en los años 1859-1880, varió entre 50 y 90. De 1881 a 1903, pasó de 80 a 146. El Asilo de Ancianos no se inauguró hasta 1887. Ana María Rodríguez Martín, "El Hospicio de Pontevedra, 1853-1903”, Pontevedra. Revista de estudos, 24 (2015), págs. 148, 165 y 167.

${ }^{114}$ Censo de la población de España según el empadronamiento verificado el 31-12-1887, vol. I.2, Madrid, Dirección General del Instituto Geográfico y Estadístico, 1892, págs. 484-585 y 742. Censo de la población de España según el empadronamiento hecho en la Península e islas adyacentes en 31-12-1900, vol. IV, Madrid, Dirección General del Instituto Geográfico y Estadístico, 1907, págs. 180-181. Apuntes para el estudio y la organización en España de las instituciones de beneficencia y previsión, Madrid, Tipografía
} 
Dentro del Hospicio, los asilados, además de pasar estrecheces ${ }^{115}$, estaban sujetos a una severa disciplina que tenía como base un reglamento que establecía una serie de castigos para sus infractores. Su dureza provocó, en la década de los ochenta y los noventa del siglo XIX, las críticas de diversos periódicos. El Hospicio, en estos casos, actuaba con celeridad y casi inmediatamente se producía el desmentido, que transformaba las expulsiones y los castigos demasiado rigurosos en salidas voluntarias y en castigos proporcionados, "correcciones impuestas por el capataz con sobrada justicia a unos cuantos díscolos que se permitieron faltas de respeto hacia sus superiores" ${ }^{\prime 16}$. No obstante, los rumores de demasiada severidad se producían cada año, y tras recogerlos la prensa, venía la aclaración,

\begin{abstract}
Un diario local dice, por referencias, que el capataz del hospicio trata con rigor a los niños (...) Hace tiempo que hemos oído la misma referencia. Nos hemos informado y nos convencimos de que era inexacta ${ }^{117}$.

Se acercó a nosotros en la mañana de ayer, una numerosa comisión de acogidos en el Hospicio de esta ciudad, suplicándonos hiciésemos constar que no es exacto que el capataz de aquel establecimiento los maltrate, sino que por el contrario los trata con la mejor consideración y cariño, condoliéndose de su desgracia, inspirándose asi en la conducta y el consejo de las madres que están al frente del benéfico asilo ${ }^{118}$.
\end{abstract}

En los hospicios el trabajo era obligatorio, pues se consideraba que era un elemento que reforzaba el orden y la disciplina, y que convertía a los acogidos en personas productivas al tiempo que los alejaba de los vicios ${ }^{119}$. En el Hospicio de Pontevedra, las asiladas se dedicaban a las labores domésticas y trabajaban en los talleres de costura. Los hospicianos se ocupaban en los talleres internos y

\footnotetext{
Sucesores de Rivadeneyra, 1909, págs. 512-515. María Luisa PéREz FARIÑA, Estructura, morfología y ritmo de la ciudad de Pontevedra y su población, tesis doctoral, Universidad de Santiago de Compostela, 1978, vol. II, pág. 3 .

115 “Puntadas", El Buscapié, 23 (7-10-1866). "Rogelio Lois", Revista Popular, 20 (20-6-1893), pág. 1, [en línea], disponible en <http://www.galiciana.bibliotecadegalicia.xunta.es> [consulta: 14-11-2016]. "Recortes y comentarios", La Unión, 442 (13-11-1898), [en línea], disponible en <http://www.galiciana.bibliotecadegalicia.xunta.es> [consulta: 14-11-2016]. A. M. ${ }^{a}$ Rodríguez Martín, "El Hospicio...", págs. 138-141.

116 "No pasa nada", La Opinión, 445 (4-8-1897).

117 "En el Hospicio", El Áncora, 375 (26-10-1898).

118 "Apuntes noticieros", El Diario de Pontevedra, 4.280 (27-10-1898).

${ }^{119}$ Ricardo CAMPOS MaRín, "La sociedad enferma: higiene y moral en España en la segunda mitad del siglo XIX y principios del XX”, Hispania, 191 (septiembre-diciembre 1995), págs. 1.100-1.101.
} 
externos, en los paseos alquilando sillas y en la banda de música, que actuaba a menudo en los actos sociales que se celebraban en la Ciudad ${ }^{120}$. Además, a partir finales del siglo XIX, los asilados asistían a los entierros de gente distinguida de Pontevedra o relacionada con el Hospicio ${ }^{121}$.

En Sevilla, y también frente a las aglomeraciones de mendigos, en 1846 se creó el Asilo de Mendicidad de San Fernando, que tenía carácter municipal y que acogía solo a los naturales o vecinos de la ciudad. Estaba pensado para 200 personas, pero pronto se superó su capacidad y este problema no se resolvió en toda el período que consideramos ${ }^{122}$. En este centro benéfico se imponía a los albergados una severa disciplina, reforzada con el trabajo en los talleres internos o externos, en la banda de música de la Institución, o con la asistencia a entierros ${ }^{123}$.

\section{Conclusiones}

En la segunda mitad del siglo XIX, en España, una parte considerable de la población podía ver su pobreza agravada por una serie de adversidades $\mathrm{y}$, sin embargo, no lograr ayuda alguna ni conseguir una plaza en un centro benéfico. Ante esta situación, algunos pobres recurrían, de forma ocasional o permanente, a la mendicidad. La postura a favor de su prohibición fue cobrando fuerza a lo largo del período que consideramos, tanto en la prensa como entre los reformadores sociales, al mismo tiempo que la imagen del mendigo iba siendo cada vez más negativa, hasta llegar a ser considerado un parásito y un peligro social y sanitario. Respecto a la mendicidad infantil, la opinión generalizada era que debía prohibirse porque favorecía la explotación de los niños y su corrupción. Esta mendicidad se achacaba a la irresponsabilidad paterna, no a la pobreza ni a las circunstancias adversas por las que podían pasar sus progenitores ni a la ausencia de éstos a causa, en la mayoría de los casos, de fallecimiento. Vemos, pues, que la mendicidad de

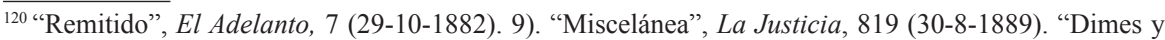
diretes", Pontevedra en broma, 1 (26-7-1892). "Cajón de sastre", El Obrero, 68 (10-7-1899). "Ecos provinciales", La Unión Nacional, 88 (14-7-1900). "Crónica provincial” y “Crónica provincial”, El Áncora, 1.318 y 1.381 , respectivamente (30-12-1901 y 17-3-1902, respectivamente). Xosé FAriÑa JAMARdo y Miguel Pereira Figueroa, A Deputación de Pontevedra, 1836-1986, Pontevedra, Diputación Provincial, págs. 342 y 350 .

121 “Apuntes noticieros", El Diario de Pontevedra, 3.886 (2-6-1897). "El trabajo de los niños", El Diario de Pontevedra, 4.051 (19-1-1898). "Sabino González Besada”, La Correspondencia gallega, 2.570 (30-71898), [en línea], disponible en <http:/www.galiciana.bibliotecadegalicia.xunta.es $>$ [consulta: 15-11-2016]. “Apuntes noticieros", Diario de Pontevedra, 4.376 (24-2-1899). "D. Antonio Licer”, La Correspondencia gallega, 2.756 (14-3-1899), [en línea], disponible en <http:/www.galiciana.bibliotecadegalicia.xunta.es> [consulta: 15-11-2016]. "Los que mueren”, El Diario de Pontevedra, 4.594 (5-9-1899). "El Sr. Cobián Areal”, El Diario de Pontevedra, 5.093 (17-5-1901). "Crónica provincial”, El Áncora, 1.812 (3-10-1903).

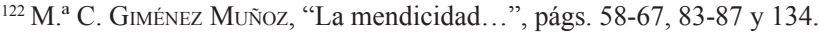

${ }^{123}$ M. ${ }^{\text {a }}$ C. GimÉNEZ MuÑOz, El Asilo..., págs. 57, 84 y 115-116.
} 
los adultos y de los niños se presentaba como una decisión personal de los propios interesados o de sus padres, y no como una responsabilidad de la sociedad y de los grupos que la dominaban, y mucho menos como el resultado de una estructura económica y social determinada.

La prensa de Pontevedra también ofrecía una imagen negativa de los mendigos, a los que reprochaba que se hubieran buscado un medio de vida cómodo, que no quisieran trabajar a pesar de existir puestos de trabajo, que fueran cada vez más numerosos y, ya en el último cuarto del siglo XIX, que se encontrasen al borde de la delincuencia. Sin embargo, estos periódicos no tenían en cuenta que Pontevedra era una ciudad con muy poca industria, que generaba muy pocos puestos de trabajo y que la mayoría de sus habitantes vivía en muy malas condiciones. Respecto a los niños mendigos, la prensa pontevedresa decía recoger las quejas de los ciudadanos por las molestias que causaban y por la imagen negativa que daban de la Ciudad, y les vaticinaba un futuro en la prostitución o el presidio.

Frente a la mendicidad se tomaron diversas medidas, tendentes primero a reducirla y luego a eliminarla, y todas resultaron fallidas. Así, se efectuaron distribuciones temporales de alimentos en situaciones críticas y se legisló sobre la mendicidad. Aunque el Código Penal de 1848 castigaba la mendicidad, y el de 1870 solo la consideraba un agravante, una buena parte de los consistorios la prohibió, total o parcialmente. Sin embargo, la reiteración de esta medida en bandos y edictos muestra su fracaso, y lo mismo ocurrió con la orden de la expulsión a sus pueblos de procedencia de los pedigüeños rurales, que la prensa sostenía que eran mayoría. La prohibición de la mendicidad, que solo pretendía quitar de las calles esta manifestación de la pobreza sin atacar sus raíces, no fue efectiva. Respecto a la mendicidad infantil, la ley de 1878 que castigaba a los que cedieran niños a individuos que se dedicaran a la mendicidad, y la de 1903 que prohibía limosnear a los menores de 16 años, tampoco fueron observadas en el período que analizamos, como denunciaban algunos periódicos pontevedreses y especialistas en el tema.

La prensa pontevedresa y muchos tratadistas reclamaban la reclusión de los mendigos en los asilos u hospicios, a pesar de que éstos tenían un número de plazas claramente insuficiente para la población ya pauperizada. Las ventajas que la reclusión presentaba, según sus defensores, eran muchas: se eliminaba el peligro sanitario que los pordioseros suponían para el conjunto de la población, se les inculcaban los valores burgueses de la jerarquía, la disciplina y el amor al trabajo para, así, anular su peligrosidad social y, por último, se eliminaba el espectáculo deplorable que ofrecían en las ciudades. 


\section{BIBLIOGRAFÍA ${ }^{124}$}

Alonso Álvarez, Luis, "La crisis de la economía tradicional: continuidad y cambio en la Galicia del siglo XIX”, en Jesús de Juana y Julio Prada (coords.), Historia contemporánea de Galicia, Barcelona, Ariel, 2005, págs. 33-56.

Alzola y Minondo, Pablo, La mendicidad y la vagancia, Bilbao, Imprenta de la Casa de Misericordia, 1902.

Apuntes para el estudio y la organización en España de las instituciones de beneficencia y previsión, Madrid, Tipografía Sucesores de Ribadeneyra, 1909.

Arenal, Concepción, La beneficencia, la filantropía y la caridad, Madrid, Imprenta del Colegio de Sordomudos y Ciegos, 1861.

Arenal, Concepción, "La mendicidad", La Voz de la Caridad, 155 (15-8-1876), págs. 161-163.

Arenal, Concepción, “De la mendicidad”, La Voz de la Caridad, 156 (1-9-1876), págs. 177-180.

Arenal, Concepción, "Los niños”, La Voz de la Caridad, 158 (1-10-1876), págs. 211-214.

Arenal, Concepción, "La Caridad en Ávila”, La Voz de la Caridad, 177 (15-7-1877), págs. 135-137.

Arenal, Concepción, "Al pueblo de su naturaleza”, La Voz de la Caridad, 244 (1-5-1880), págs. 41-46.

Arenal, Concepción, "Al pueblo de su naturaleza”, La Voz de la Caridad, 245 (15-5-1880), págs. 61-66.

Arenal, Concepción, “Al pueblo de su naturaleza”, La Voz de la Caridad, 246, (1-6-1880), págs. 73-80.

Arenal, Concepción, La instrucción del pueblo, Madrid, Real Academia de Ciencias Morales y políticas, 1881 .

Arenal, Concepción, "Persecución de mendigos", La Voz de la Caridad, 271 (5-6-1881), págs. 97-99.

Arenal, Concepción, "Niños expósitos y niños mendigos", Boletín de la Institución Libre de Enseñanza, vol. XI (1887), págs. 369-374.

Arenal, Concepción, Artículos sobre beneficencia y prisiones, Madrid, Librería de Victoriano Suárez, 1901.

Arenal, Concepción, “La educación de la mujer”, El Diario de Pontevedra, 5.217 (9-10-1901).

Arenal, Concepción, “Los niños”, El Diario de Pontevedra, 5.295 (22-1-1902).

Arenal, Concepción, “Los niños pobres”, El Diario de Pontevedra, 5.610 (27-12-1902).

Arenal, Concepción, "Los niños", La Correspondencia gallega, 4.176, (29-12-1903).

Artiaga Rego, Aurora, "La sociedad gallega (1775-1874)", en Jesús de Juana y Julio Prada (coords.), Historia contemporánea de Galicia, Barcelona, Ariel, 2005, págs. 57-82.

\footnotetext{
${ }^{124}$ Publicaciones periódicas consultadas: El Adelanto, 1882; El Áncora, 1897, 1898, 1901-1903; El Anunciador, 1889; El Avisador, 1881; El Buscapié, 1866-1868; El Combate, 1899-1901; El Diario de Pontevedra, 1879, 1885, 1895, 1897-1903; El Ferrocarril, 1853-1854; La Justicia, 1889-1890; El Obrero, 1898-1899; La Opinión, 1897; Pontevedra en broma, 1892; El Porvenir, 1850-1867; El Progreso, 1865, 1910; Revista de beneficencia, sanidad y establecimientos penales, 1878; La Unión Nacional, 1900-1901; La Voz de Helenes, 1883-1884; La Voz de la Caridad, 1871-1883.
} 
Aznar, Joaquín, "Los primeros fríos”, La Correspondencia gallega, 3.536 (30-10-1901).

Bahamonde Magro, Ángel y Toro Mérida, Julián, "Mendicidad y paro en el Madrid de la Restauración”, Estudios de Historia Social, 7 (1978), págs. 353-384.

Ballesteros Doncel, Esmeralda, "El coste de la vida en España (1800-1890). Diferencias entre el salario monetario y el presupuesto familiar", en Manuel González Portilla y Karmele Zarraga Sangroniz (edits.), Actas del IV Congreso de la Asociación de Demografia Histórica, Bilbao, Universidad del País Vasco, 1999, págs. 573-592.

Barreiro, Augusto, “Una chica señoritino”, El Progreso, 184 (12-6-1910).

Barreiro Fernández, Xosé Ramón, "De Isabel II a la Restauración”, en A Gran Historia de Galicia, Vol. XI, A Coruña, Editorial Arrecife, 2007.

Blanco-Belmonte, M.R., "Españolería”, La Correspondencia gallega, 3.004 (15-1-1900).

Blanco Herrero, Miguel, De la beneficencia pública en España, Madrid, J.M. Pérez, 1869.

Borderies-Guereña, Josette, "Niños y niñas en familia", en José María Borrás Llop (dir.), Historia de la infancia en la España contemporánea, 1834-1936, Madrid, Ministerio de Trabajo y Asuntos Sociales, 1996, págs. 19-106.

Braojos, Alfonso; Parias, María y Álvarez, Leandro, Historia de Sevilla. Sevilla en el s. XX (1868-1950), Sevilla, Universidad de Sevilla, 1990.

Buceta, I., “Crónica”, El Diario de Pontevedra, 9.144 (17-7-1903).

Campos Marín, Ricardo, "La sociedad enferma: higiene y moral en España en la segunda mitad del siglo XIX y principios del XX", Hispania, 191 (septiembre-diciembre 1995), págs. 1.093-1.112.

Capel, Horacio y Tatjer, Mercè, "Reforma social, serveis asistencials i higienisme a la Barcelona de final del segle XIX (1876-1900)", en Cent anys de salut pública a Barcelona, Barcelona, Ayuntamiento de Barcelona, 1991, págs. 31-73.

Carasa Soto, Pedro, Pauperismo y revolución burguesa: Burgos, 1750-1900, Valladolid, Universidad de Valladolid, 1987.

Carasa Soto, Pedro, "La Historia y los pobres: de las bienaventuranzas a la marginación", Historia Social, 13 (1992), págs. 77-99.

Cardín Zapata, Julio, "Pobres niños”, La Voz de la Caridad, 315 (15-4-1883), págs. 44-47.

Castro, Xavier, "Introducción á historia do movemento obreiro galego", en Jesús de Juana y Xavier Castro (eds.), III Xornadas de Historia de Galicia. Sociedade e movemento obreiro en Galicia, Ourense, Diputación Provincial, 1986, págs. 185-222.

Castro, Xavier, Historia da vida cotiá en Galicia. Séculos XIX e XX, Vigo, Nigratea, 2007.

Censo de la población de España según el empadronamiento verificado el 31-12-1887, vol. I y II, Madrid, Dirección General del Instituto Geográfico y Estadístico, 1892.

Censo de la población de España según el empadronamiento hecho en la Península e islas adyacentes en 31-12-1900, vol. IV, Madrid, Dirección General del Instituto Geográfico y Estadístico, 1907.

Cerdá, Ildefonso, Teoría General de la urbanización y aplicación de sus principios y doctrinas a la reforma y ensanche de Barcelona, Madrid, Imprenta Española, 1867.

Código Penal de España, Barcelona, imprenta de Manuel Saurí, 1850.

Código Penal de 1870, Valencia, Librería de P. Aguilar, 1889. 
Codina Langlín, Ramón, Organización de la Casa Provincial de Caridad y de la Casa Provincial de Maternidad y Expósitos de Barcelona, Barcelona, Imprenta de la Casa Provincial de Caridad, 1889.

Cordespall, Elena de, "Variedades", El Correo de Lugo, 2 (25-5-1860).

Cossío y Gómez Acebo, Manuel, El problema de la mendicidad en los grandes centros de población, Madrid, Imprenta de J. Sastre y Cia., 1909.

Cuenca Toribio, J. Manuel, Historia de Sevilla. Del Antiguo al Nuevo Régimen, Sevilla, Universidad de Sevilla, 1986.

Díaz Martínez, Carlos; Freixanes, Víctor F. y Fortes Bouzán, Xosé, A memoria de Pontevedra, Vigo, Edicions Xerais, 2001.

Díez Rodríguez, Fernando, "Estructura social y sistema benéfico asistencial en la ciudad preindustrial", Historia social, 13 (1992), págs. 101-121.

Domínguez Adame, Francisco, "Causas de la excesiva mortalidad en la primera infancia en las grandes ciudades y medios de atenuarlas", en Actas del Congreso Médico Internacional de Sevilla, Sevilla, Imprenta de Carlos M. Santigosa, 1882, págs. 220-230.

Espino Jiménez, Francisco Miguel, "Actitud social y regulación de la mendicidad en el liberalismo: las normas contra "vagos" en la Córdoba isabelina", Ámbitos, 17 (2007), págs. 29-39 [en línea], disponible en $<$ http://dialnet.unirioja.es/servlet/extaut?código=519912> [consulta: 8-4-2015].

Estarán Molinero, José, La Caridad, centenaria: sus primeros años (1898-1910), Zaragoza, Ayuntamiento de Zaragoza, 2000.

Esteban de Vega, Mariano, "La asistencia liberal española: beneficencia pública y previsión particular”, Historia social, 13 (1992), págs. 123-138.

Fariña Jamardo, Xosé y Pereira Figueroa, Miguel, A Deputación de Pontevedra, Pontevedra, Deputación Provincial, 1986.

Fernández Leiceaga, Xaquín, "Poboación e crescimento económico na Galiza do século XX", en Jesús de Juana y Xavier de Castro (dirs.), XXornadas de Historia de Galicia. Grandes transformacións na Historia contemporánea de Galicia, Ourense, Deputación Provincial, 1998, págs. 123-147.

Fernández Soler, Cosme, Descripción de Pontevedra, Pontevedra, Imprenta de la Unión Republicana, 1890.

Feu, José Leopoldo, Extinción de la mendicidad, Barcelona, Ateneo Catalán, 1862.

Fortes Bouzán, Xosé, Historia de la ciudad de Pontevedra, A Coruña, La Voz de Galicia, 1993.

Fresquet Febrer, José Luis, Francisco Méndez Álvaro (1806-1883) y las ideas sanitarias del liberalismo moderado, Madrid, Ministerio de Sanidad y Consumo, 1990.

Fuentes Nieto, $\mathrm{M}^{\mathrm{a}}$ Carmen, "Una institución benéfica en la Málaga del siglo XIX: la Casa de Mendicidad”, Jábega, 93 (2003), págs. 20-34.

Galván González, Encarna. "Pobreza y mendicidad en Las Palmas de Gran Canaria durante la segunda mitad del siglo XIX. Actitud municipal frente al problema", Boletín Millares Carlo, 15 (1996), págs. 61-74.

García García, Cristóbal y Butrón Prida, Gonzalo, "La realidad social andaluza en el siglo XIX”, en Leandro Álvarez Rey y Encarnación Lemus López (eds.), Historia de Andalucía contemporánea, Huelva, Universidad de Huelva, 1998, págs. 181-210. 
Giménez Muñoz, María del Carmen, El Asilo de Mendicidad de San Fernando (1846-1900), Sevilla, Universidad de Sevilla, 2006.

Giménez Muñoz, María del Carmen, "La mendicidad en la capital hispalense (1850-1900): bandos municipales”, Archivo Hispalense, 273-275 (2007), págs. 113-137.

González del Alba, P., "Niños abandonados”, El Diario de Pontevedra, 5.367 (22-4-1902).

González Revilla, Gerardo, La protección de la infancia abandonada: abandono y criminalidad de los niños, Bilbao, Tipográfica Popular, 1907.

Guerola, Antonio, “Los Asilos del Pardo", La Voz de la Caridad, 95 (15-2-1874), págs. 357-359.

Hauser, Philippe, Estudios médicos de Sevilla, Madrid, Librería de Victoriano Suárez, 1884.

Hernández Borges, Julio, Dinamismo y estructura de la población de Pontevedra, 1900-1970, Santiago de Compostela, Universidad de Santiago de Compostela, 1974.

Hernández Iglesias, Fermín, "El mal social”, La voz de la Caridad, 262 (1-2-1881), págs. 298-305.

Hernández Iglesias, Fermín, “El mal social”, La Voz de la Caridad, 280 (1-11-1881), pág. 250.

Ibarzabal Aramberri, Xavier, "Pobreza y mendicidad en Donostia a finales del siglo XX", Boletín de la Real Sociedad Bascongada de los Amigos del País, 1 (1999), págs. 121-138.

Juderías, Julián, El problema de la mendicidad en los grandes centros de población, Madrid, Imprenta de J. Sastre y Cia., 1909.

Juderías, Julián, La infancia abandonada, Madrid, Tipografía de Jaime Ratés, 1912.

Juderías, Julián, La juventud delincuente, Madrid, Tipografía de Jaime Ratés, 1912.

Jutglar, Antoni, "Actitudes conservadoras ante la realidad obrera en la etapa de la Restauración”, Revista del Trabajo, 25 (1969), págs. 45-71.

Leyes y disposiciones vigentes de Protección a la Infancia, Madrid, Imprenta del Asilo del Huérfanos del Sagrado Corazón de Jesús, 1908.

López Mora, Fernando, Pobreza y sociedad en Córdoba, (1750-1900): de la caridad a la beneficencia pública, Córdoba, Universidad de Córdoba, 1992.

López Mora, Fernando, "Mendicidad y acción social en la Córdoba de la Restauración", Boletín de la Real Academia de Córdoba de Ciencias, Bellas Letras y Nobles Artes, 65 (1994), págs. 357-371 [en línea], disponible en <http://www.helvia.uco.es/xmlui/bistream/ handle/10396/.../braco127_1994_1.pdf> [consulta: 9-4-2015].

López Núñez, Álvaro, Los inicios de la protección social a la infancia en España, Madrid, CEPE, 1992.

López Taboada, José Antonio, La población de Galicia, 1860-1991, A Coruña, Fundación Caixa Galicia, 1996.

Llorens y Gallard, Ignacio, La mendicidad en Barcelona, Tipografía de la Casa Provincial de Caridad, Barcelona, 1892.

Mateo Avilés, Elías, Paternalismo burgués y beneficencia religiosa en la segunda mitad del siglo XIX, Málaga, Diputación Provincial, 1986.

Maza Zorrilla, Elena, Pobreza y asistencia social en España, siglos XVI al XX, Valladolid, Universidad de Valladolid, 1987.

Maza Zorrilla, Elena, Pobreza y beneficencia en la España contemporánea (1808-1936), Madrid, Ariel, 1999. 
Monlau, Pedro Felipe, De la supresión de la mendicidad y organización de las Juntas de Caridad, Madrid, Imprenta del Colegio de Sordo-Mudos, 1851.

Moro, José María, Las epidemias de cólera en la Asturias del siglo XIX, Oviedo, Universidad de Oviedo, 2003.

Muñiz de las Cuevas, Ramón, O pobo oculto: pobreza y acción social en Galicia, Vigo, Edicions A Nosa Terra, 1996.

Murguía, Manuel, "La miseria en Galicia”, La Ilustración gallega y asturiana, vol. II, núm. 14 (20-5-1880), pág. 17.

Nin y Tudó, Joaquín, Tres problemas: la extinción de la mendicidad, mejorar la situación del proletariado, instrucción popular, Barcelona, Luis Tasso impresor, 1901.

Ordenanzas municipales de la ciudad de Pontevedra, Pontevedra, Nueva imprenta de las dos A.N. Pazos y Antúnez, 1850.

Ordenanzas municipales del Excelentísimo Ayuntamiento del Pontevedra, Pontevedra, Tipografía de la Viuda e Hijos de Carrafal, 1905.

Palacio Lis, Irene y Ruiz Rodrigo, Cándido, Redimir la inocencia: historia, marginación infantil y educación protectora, Valencia, Universidad de Valencia, 2002.

Palomares Ibáñez, Jesús María, "La condición obrera en La Coruña a finales del siglo XIX", en Jesús de Juana y Xavier Castro (eds.), II Xornadas de Historia de Galicia. Aspectos da realidade galega (Séc. XVI ó XX), Ourense, Diputación Provincial, 1986, págs. 43-84.

Peña Santos, Antonio de la; Juega de Guereñu Polán, Luis y López de Guereñu Polán, Luis, Historia de Pontevedra, A Coruña, Vía Láctea, 1996.

Pérez Fariña, María Luisa, Estructura, morfología y ritmo de la ciudad de Pontevedra y su población, tesis doctoral, Universidad de Santiago de Compostela, 1978.

Pernas Oroza, Herminia, Historia das mulleres en Galicia, época contemporánea, Baiona, Nigratea y Xunta de Galicia, 2011.

Puy i Juanico, Josep, Pobres, desvalguts $i$ asilats: caritat $i$ beneficència a la Catalunya del segle XIX, Barcelona, Publicacions de l'Abadia de Montserrat, 2009.

Reglamento del Asilo de Mendicidad de San Bernardino, Madrid, Junta Municipal de Beneficencia, 1855.

Reglamento del Asilo Local de Mendicidad, A Coruña, Tipografía “La Gutemberg”, 1895.

Reglamento interior para el Asilo de Mendicidad de La Coruña, A Coruña, Imprenta del Hospicio Provincial, (s.a.).

Reglamentos para el régimen interior de los establecimientos provinciales de beneficencia, Salamanca, Imprenta del Hospicio, 1886.

Rodríguez Galdo, Ma Xosé, “A economía en Galicia no século XIX”, en Jesús de Juana y Xavier Castro (dirs.), II Xornadas de Historia de Galicia. Aspectos da realidade galega (Séc. XVI ó XX), Ourense, Deputación Provincial, 1986, págs. 109-134.

Rodríguez Martín, Ana María, Las mujeres y la beneficencia en la segunda mitad del siglo XIX. La Casa Provincial de Maternidad y Expósitos de Barcelona, 1853-1903, tesis doctoral, Universidad de Barcelona, 2005.

Rodríguez Martín, Ana María, "El Hospicio de Pontevedra, 1853-1903”, Pontevedra. Revista de estudos, 24 (2015), págs. 123-191. 
Román Portas, Luz, La asistencia social en Galicia: el Hospicio de Pobres de Santiago de Compostela (1860-1900), A Coruña, Diputación Provincial, 1989.

Ruiz Rodrigo, Cándido, "Mendicidad infantil, trabajo y educación, en el marco de las políticas sociales de comienzos del siglo XX", en Doctor Buenaventura Delgado Criado. Pedagogo e historiador, Barcelona, Universidad de Barcelona, 2009, págs. 587-607.

Ruiz Rodrigo, Cándido y Palacio Lis, Irene, Pauperismo y educación. Siglos XVIII y XIX, Valencia, Universidad de Valencia, 1995.

Salarich, Joaquín, Higiene del tejedor, Vic, Imprenta Soler Hermanos, 1858.

Salas, Nicolás, Sevilla: crónicas del siglo XX, 1895-1920, vol. I, Sevilla, Universidad de Sevilla, 1991.

Sallarés Pla, Juan, El trabajo de las mujeres y los niños, Sabadell, Imprenta A. Vives, 1892.

Salvá, Melchor, "Relación histórica de la Sociedad", Revista Económica: periódico agrícola, artístico y comercial de la Sociedad de Amigos del País de Santiago, 57 (15-3-1863), págs. 180-186.

Santolaria, Félix, Marginación y educación, Barcelona, Ariel, 2000.

Santos Sacristán, Marta, "Una aproximación a la Ley de Mendicidad de 1903”, Revista de la Inquisición, 16 (2012), págs. 227-260.

Sotelo Resurrección, Enrique, Pontevedra, 1840-1915, Pontevedra, Diputación Provincial, 1997.

Tamariz y Eguía, Ramón, Estudio sobre la vagancia y la mendicidad voluntaria, Madrid, Tipografía de los Huérfanos, 1890.

Torres Ruiz, José Antonio, "Un ejemplo de beneficencia municipal en el s. XIX: el Asilo de Mendicidad de León”, Tierras de León, 126-127 (2008), págs. 103-130, [en línea], disponible en <http://www.saber.es/web/biblioteca/libros/tierras-de-leon/html/126-127/ tierras-de-leon-126-127.pdf > [consulta: 15-9-2015].

Trinidad Fernández, Pedro, "La infancia delincuente y abandonada”, en José María Borrás Llop (dr.), Historia de la infancia en la España contemporánea, 1834-1936, Madrid, Ministerio de Trabajo y Asuntos Sociales, 1996, pags. 459-522.

Valverde Lamsfus, Lola, "Estrategias de supervivencia de las mujeres pobres en Guipúzcoa. Los casos de San Sebastián y Tolosa (1885-1915)", Historia Contemporánea, 44 (2012), págs. 183-202 [en línea], disponible en <http://www.ehu.eus/ojs/index.php/HC/article/ view/6610> [consulta: 3-4-2015].

Varela de Montes, J., sin título, Boletín del cólera, 11 (30-5-1854), pág. 2.

Vega-Rey, Luis, Pobreza y mendicidad, Madrid, Imprenta Enrique Teodoro, 1885.

Velasco Mesa, Custodio, "La mendicidad en el discurso de la prensa sevillana, 18981900: de "problema social" a "amenaza de la multitud miserable", Revista de Historia Contemporánea, 6 (1995), págs. 241-264.

Velasco Mesa, Custodio, Los nombres de la "cuestión social". Discursos y agitaciones obreras: Lieja y Sevilla en el tránsito de los siglos XIX y XX, Sevilla, Diputación Provincial, 2003.

Velasco Souto, Carlos F., A sociedade galega da Restauración na obra literaria de Pardo Bazán (1875-1900), (s.1., s.n.), d.1. 1987.

Zancada, Práxedes, El obrero en España, Barcelona, Maucci, 1902. 
